\title{
Urbanization impact on metals mobility in riverine suspended sediment: Role of metal oxides
}

\author{
${ }^{*}$ C. Priadi; S. Ayrault; S. Pacini; P. Bonte \\ Laboratoire des Sciences du Climat et de l'Environnement (LSCE/IPSL, CEA-CNRS-UVSQ) avenue de la terrasse, \\ 91198 Gif sur Yvette cedex, France
}

Received 22 June 2010; $\quad$ revised 4 October 2010; accepted 25 November 2010

\begin{abstract}
Spatial and temporal fractionation of trace metals and major elements in suspended particulate matter in the Seine River was investigated to study the impact of the increasing urbanization in the Greater Paris Region. Suspended sediments in the Seine River were collected between December 2008 to August 2009 upstream and downstream of Paris. They were subjected to total digestion and sequential extraction procedure certified by the Bureau Communautaire de Référence and trace metals along with major elements were analyzed with inductively coupled plasma mass spectroscopy. Metal enrichment factors increased up to eight folds after the Seine River downstream of the Greater Paris Region showing a significant contribution of urbanization. Enrichment of copper, lead and zinc downstream of Paris are followed by the increase of their reducible fraction of at least $10 \%$ implicating an increase in metals associated with iron oxides. The exchangeable fraction, which includes the carbonate-associated metals, is only significant for cadmium, nickel and zinc (more than $2 \%$ ) while the oxidisable fraction accounts for less than $20 \%$ for the anthropogenic metals downstream except for copper. The metals can be divided to (a) "reducible” group including cadmium, lead, and zinc, associated with more than $60 \%$ of the total Bureau Communautaire de Référence extractable metals to the reducible fraction containing mostly iron oxide phases for the downstream sites. (b) A "distributed" group including chromium, copper, and nickel that are associated to at least 3 different phase-groups: (1) oxides, (2) organic matter and sulphides and (3) mineral phases.
\end{abstract}

Keywords: Carbonate; Enrichment factor; Pollution; Reducible fraction; Sequential extraction

\section{INTRODUCTION}

In the last decade, metal contamination in urban continental aquatic system has been a growing concern (Sekabira et al., 2010; Mohiuddin et al., 2010). Impacts of anthropogenic activities on metal contamination in a watershed are far from being insignificant (Horowitz et al., 1999; Davis et al., 2001; Taylor and Owens, 2009; Igbinosa and Okoh, 2009). They are known to generate a considerable amount of metal to the environment through various pathways including atmospheric particles (Azimi et al., 2005; Zhu et al., 2009), urban runoff (Gromaire-Mertz et al., 1999; Igwe et al., 2008), industrial and wastewater effluents (Buzier et al., 2006; Nwuche, 2008; Shah et al., 2009). Urbanization impacts on metal contamination concern watersheds inhabiting more than $50 \%$ of the world population (Meybeck, 2003). The Seine River watershed is home to $25-30 \%$ of French industries, $23 \%$ of French constantly increasing

*Corresponding Author Email: cindy.priadi@lsce.ipsl.fr Tel.: +33 16982 4362; Fax: +33 169824362 urban and agricultural activities contribute to metallic aquatic contamination. In the last two decades, many institutions carried out actions in the Seine River to understand pollutant behaviour with parallel decontamination. Since then, the concentration of trace elements such as the $\mathrm{Cd}, \mathrm{Cr}, \mathrm{Cu}, \mathrm{Ni}, \mathrm{Pb}$, and $\mathrm{Zn}$ showed a significant decline measured in dated sediment cores (Le Cloarec et al., 2009). Nevertheless, due to very high anthropogenic pressures and very limited dilution power, the Seine River downstream of Greater Paris is still among the world's most contaminated rivers (Meybeck et al., 2007). Despite the decreasing concentrations in the solid phases, Elbaz-Poulichet et al. (2006) still found moderate contamination of dissolved metals in the water column of the Marne and Seine Rivers. Various studies contributed to the understanding of metal behaviour in different compartments due to the dynamic metal distribution between different phases in the water column. In the 
Seine River, the value and dynamics of dissolved Mn, $\mathrm{Cu}, \mathrm{Cd}$ and Mo were partly attributed to variation in redox condition (Elbaz-Poulichet et al., 2006). Shorttime extreme variation of dissolved $\mathrm{Zn}$ is also observed using high-definition sampling (Pepe et al., 2008). Depending on the element, the solid fraction holds 50$90 \%$ of the anthropogenic metal stock (Cd, Cu, Cr, Zn, and $\mathrm{Pb}$ ) in the Seine River water column (Thévenot et al., 2007). Furthermore, floodplain and bed sediments contain a large stock of historical deposit and contamination. Therefore, this solid fraction plays an important role in metal contamination as it may release heavy metal to the water column, as well as scavenging them. It is then necessary to understand the behaviour and distribution of trace elements in the different solid phases and their mobility towards the dissolved fraction. The latter, more specifically the labile fraction, represent the bio-available fraction. Moreover, the solid fraction may hold evidences of metal sources and formation processes. The study of metal speciation in the solid fraction may therefore help us understand the contribution of different sources and biogeochemical processes in the formation and mobility of metal in the solid phase.

Metal speciation studies such as the sequential extraction are often performed on mining-impacted rivers (Da Silva et al., 2002; Galan et al., 2003; Audry et al., 2006; Lesven et al., 2009) but rarely on non-mining urban watershed even though urban anthropogenic activities can generate a specific characteristic of metal speciation in a water course (Garnaud, 1999; Dali-Youcef et al., 2004; Carter et al., 2006; Sutherland and Tack, 2007). Interpretation are also rarely compared by simultaneous extraction of major elements originating from the metalbearing particles including $\mathrm{Ca}, \mathrm{Fe}, \mathrm{Mn}$, and $\mathrm{Mg}$, except for a few studies (Gagnon et al., 2009; Li et al., 2009; Vieira et al., 2009). Tongtavee et al. (2005) have shown that the analysis of extracted major elements is of great interest to understand lead speciation in soils affected by mining activities.

Despite the Seine River basin's great economic importance and the many articles published on contents and behaviour in dissolved and labile fraction of trace metals in the Seine River (Elbaz-Poulichet et al., 2006; Tusseau-Vuillemin et al., 2007; Chen et al., 2009; Jouvin et al., 2009), trace metal speciation on solid fraction were only conducted on average suspended matter from 3 sites (Taconet, 1996) and urban source-related samples (Garnaud, 1999). According to these studies, metal mobility can be ranked as follows: $\mathrm{Cu}<<\mathrm{Cd}<\mathrm{Pb}<\mathrm{Zn}$. Nevertheless, these studies do not detail the temporal variation of the metal distribution, and spatial variation was concluded from only one sampling in three sites.

This study is therefore aimed to investigate anthropogenic impact on the temporal and spatial variability of metal speciation and understand heavy metal mobility in the Seine River suspended particulate matter (SPM) through the BCR sequential extraction with preliminary study focusing on efforts on reducing working weight. A one-year study was conducted in three characteristic sites of the Seine River. The solid speciation of six metals (Cd, $\mathrm{Cr}, \mathrm{Cu}, \mathrm{Ni}, \mathrm{Pb}$ and $\mathrm{Zn}$ ) along with nine major elements was determined.

\section{MATERIALSAND METHODS}

\section{Location}

Seven monthly samplings from December 2008 August 2009 were conducted in the 3 study sites along the Seine River (Fig. 1). The sampling scheme aims to distinguish the impacts of two sources of anthropogenic influence to the Seine River which have previously been observed. First source is the area of Greater Paris, including the most urbanised area in the region with more than 3700 habitants $/ \mathrm{km}^{2}$. Second is the wastewater treatment plant WWTP Paris-Aval (formerly known as Achères) treating around 1.7 million $\mathrm{m}^{3}$ per day (SIAAP, 2007). The first sampling site is located at Marnay-surSeine, situated in far upstream of the Seine River. It was chosen to represent a relatively pristine site nonaffected by the Greater Paris region, where the Seine is a 6 Strahler order river. The second site is the Seine at Bougival, a Strahler order 7 River situated $40 \mathrm{~km}$ downstream of Paris. It was chosen to represent the impact of Paris without the influence of the WWTP Paris-Aval. Another $40 \mathrm{~km}$ further downstream, Trielsur-Seine was selected to represent the impact of Paris along with the Paris-Aval after the confluent of the Seine River with the Oise River, making it a Strahler order 8 . The Seine River is affected mainly by the sedimentary basin mostly containing carbonate rocks (Meybeck et al., 1999). The flow regime is low from July to September and high flows are observed from January to March (Fig. 2).

\section{Sampling and sample treatment}

Materials and sample handling were done in a systematic clean method. All bottles and containers were soaked in $2 \mathrm{~N} \mathrm{HNO}_{3}$ during at least 3 days. Afterwards they were rinsed thoroughly 3 times with 


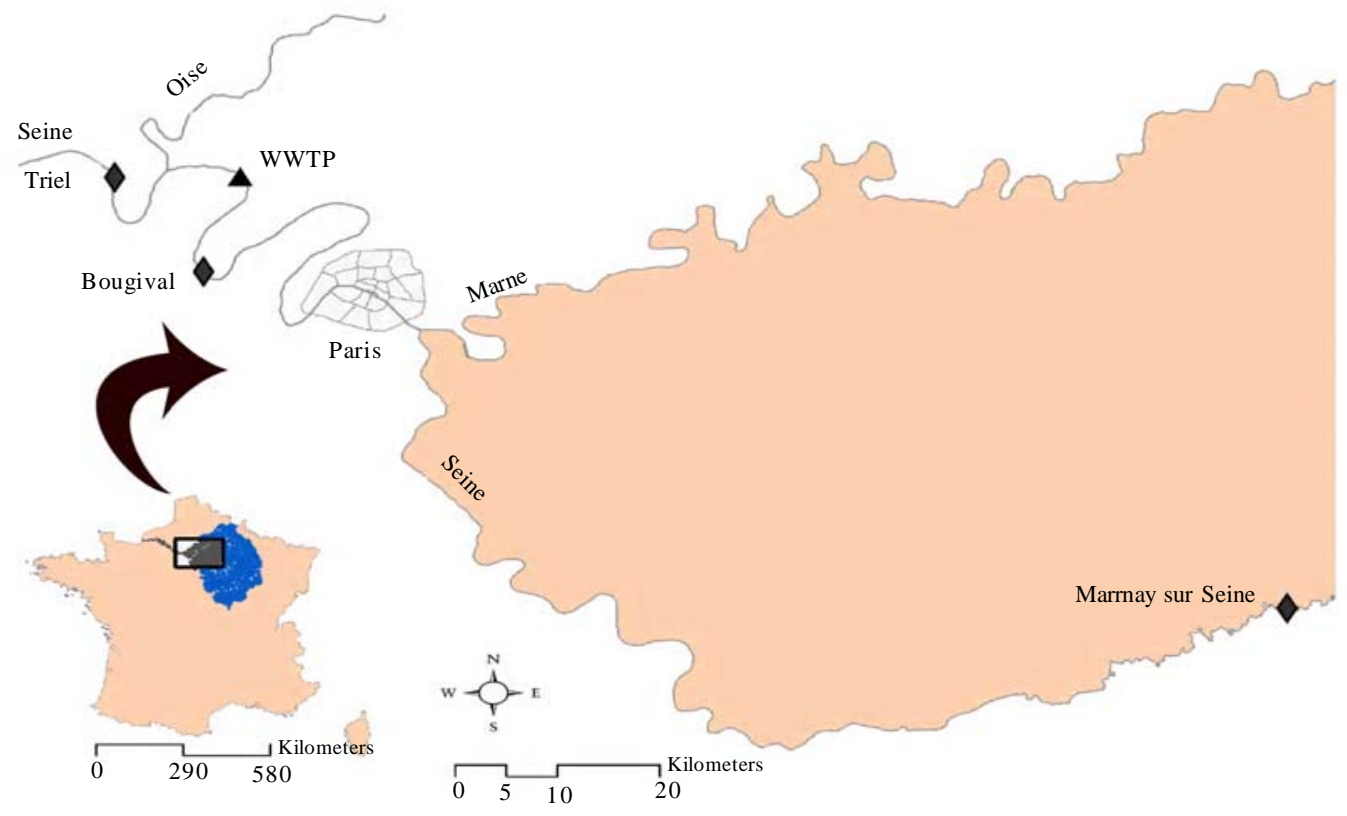

Fig. 1: Sampling sites marked with diamonds; from upstream to downstream: Marnay sur Seine, Bougival, and Triel. Black triangle indicates Seine-Aval waste water treatment plant

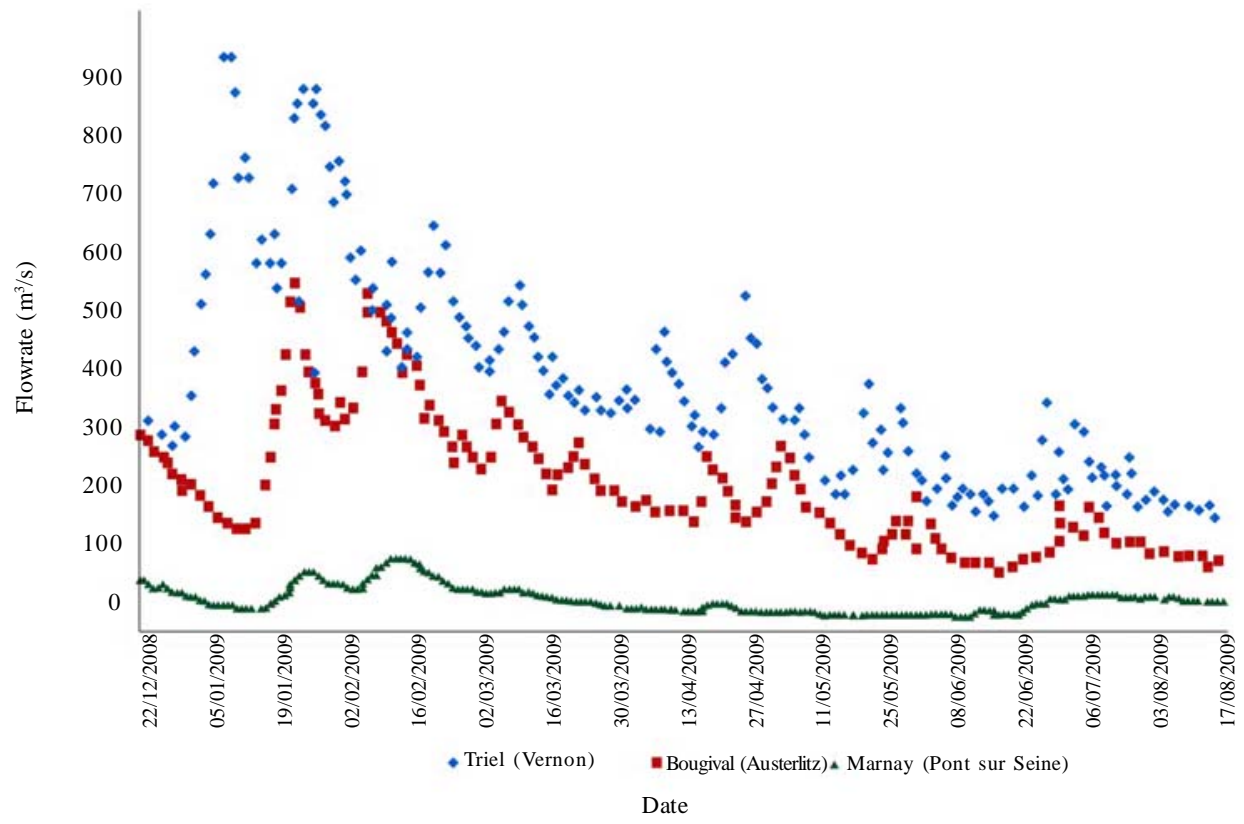

Fig. 2: Evolution of daily flow measured at 3 sites similar to the study sites of this paper measured by the Syndicat Intercommunal d'Assainisement de l'Agglomération Parisienne (SIAAP) 
de-ionised water. All bottles and containers were rinsed 3 times with river water before handling the samples.

To obtain enough SPM for sequential extraction purposes, a sediment trap was installed in each site. It consisted of a 2 L PVC water bottle hanged from at least $1 \mathrm{~m}$ from the river bank at mid-depth. Two holes of a diameter of around $4 \mathrm{~cm}$ were carved on two sides on the upper side of the bottle with the two holes posed creating a parallel axe to the river flow. This method was previously successfully used by Tessier and Bonté (2002) to collect the Seine SPM. SPM from sediment trap was emptied in a polyethylene bottle on field along with uplying water. Samples were transported and stored in the dark at $4{ }^{\circ} \mathrm{C}$ before analysis. Storage duration ranged from 2 days to one month before sample treatment.

Samples were then centrifuged in the laboratory at $3500 \mathrm{rpm}$ for $20 \mathrm{~min}$ for several cycles until all the water are centrifuged and all the SPM are recovered. It was then freeze-dried for at least $48 \mathrm{~h}$ and homogenized with agate mortar. Samples were then stored in acidcleaned glass jars in the dark before analysis.

\section{Solid phase analyses}

Bulk digestion

To obtain total metal contents, $0.1 \mathrm{~g}$ of SPM was digested in Teflon vessels under laminar flow hood using a heating block (Digiprep, SCP Science). The first attack uses $10 \mathrm{~mL}$ aqua regia $\left(\mathrm{HNO}_{3} 65 \%\right.$ : $\mathrm{HCl} 30$ $\%, 3: 1$ ) for 3 days at room temperature. Excess nitrate and chloride were evaporated at $90^{\circ} \mathrm{C}$ and underlying liquid was separated ensuring the least quantity of $\mathrm{HCl}$ remaining in the vessels through rinsing 3 times with $10 \mathrm{~mL} 0.5 \mathrm{~N} \mathrm{HNO}_{3}$. Digestion continued with 10 $\mathrm{mL}$ of a $\mathrm{HF} 48.9 \%$ : $\mathrm{HNO}_{3} 65 \%$ mixture (1:1) to attack siliceous minerals during $24 \mathrm{~h}$ at room temperature. Sample was evaporated to dryness at $100^{\circ} \mathrm{C}$ to eliminate hexafluorosilicic acid. The solid residue was then attacked with $12 \mathrm{~mL}$ of a $\mathrm{HNO}_{3} 65 \%: \mathrm{HClO}_{4} 69-72 \%$ (1:1) mixture heated at $120^{\circ} \mathrm{C}$ during 5 days. Final solutions were evaporated near to dryness. $1 \mathrm{~mL}$ of 65 $\% \mathrm{HNO}_{3}$ was added to the remaining solution that was then evaporated near dryness. This step was repeated three times. The solutions were then brought into a 50 mL 0.5 $\mathrm{N} \mathrm{HNO}_{3}$ solution. This method was adapted for the Seine River carbonated SPM, and allows complete SPM digestion. The 3 day aqua regia step allowed dissolution of the abundant amount of carbonates in samples. Afterwards, underlying liquid was separated to avoid re-precipitation of the $\mathrm{Ca}$ and $\mathrm{Mg}$ fluorides in HF solution. All solutions were ultrapure reagents to assure minimum contamination $\left(\mathrm{HNO}_{3}\right.$ and $\mathrm{HCl}$ Normatom grade, VWR France, and $\mathrm{HF}$ and $\mathrm{HClO}_{4}$ “for trace metal analyses”, Baker, from Sodipro France).

\section{BCR sequential extraction}

Each BCR sequential extraction was performed on duplicates of $0.25 \mathrm{~g}$ of sediment following Revised BCR with extra rinsing to overcome the difficulty due to the smaller amount of extracting solution used. Extraction protocol is summarized in Table 1 . Due to a lack of endto-end shaker, shaking was performed using a platform orbital shaker during $16 \mathrm{~h}$ at $300 \mathrm{rpm}$ (Heidolph vibramax 100). The speed was chosen to keep the samples well in suspension without shaking excessively to avoid over-extraction. Due to the relatively low quantity of samples used, separating the extracted solution without removing the sample was a difficult task. A second rinsing was applied using half the normal volume of the same extracting solution before rinsing samples with water. Each extraction batch was accompanied by a duplicate of the BCR 701 (Bureau Communautaire de Recherches, Gent, Belgium) certified lake sediment for sequential extraction.

\section{Analytical procedure}

Major and trace metal concentration were determined in total and sequential extraction samples using Inductively Coupled Plasma Quadrupolar Mass Spectrometry (ICP-QMS) (X-Series, CCT II+ ThermoElectron, France). ICP-QMS spectrometer was calibrated using standard solutions and checked for with certified river water (SRM 1640, National Institute for Science and Technology, Gaithersburg, USA) routinely during analysis, at least once per day of analysis and once for every 20 samples at the most. Instrumental drifts and plasma fluctuations were corrected using internal standards (Re, Rh, and In (SPEX, SCP Science, France)) for all the metals studied, and Ge for major elements including $\mathrm{Ca}, \mathrm{Al}$, and $\mathrm{Mg}$. To minimise interferences, analysis with the Collision Cell Technology (CCT) introducing a supplementary gas mixture of $\mathrm{H}_{2}(7 \%)$ and $\mathrm{He}$ (93\%) was applied for Fe, Mn, and the 6 metals studied (Cd, Cr, Cu, Ni, Pb, Zn). Major elemental bulk analysis including $\mathrm{Ca}, \mathrm{Si}, \mathrm{Al}, \mathrm{Fe}, \mathrm{Mg}, \mathrm{S}, \mathrm{K}, \mathrm{P}$, and Ti were performed with micro $(50 \mu \mathrm{m}) \mathrm{X}$-ray fluorescence (XRF) (Microfocus $\mathrm{X}$-ray source IFG X-1) through measurements of pressed pellets (diameter $0.5 \mathrm{~cm}$, 
Int. J. Environ. Sci. Tech., 8 (1), 1-18, Winter 2011

Table 1 : Summary of the BCR sequential extraction protocol after Pueyo et al. (2001) except step 4 with aqua regia, added to complete protocol

\begin{tabular}{|c|c|c|c|c|}
\hline & Reagent & $\begin{array}{l}\text { Operationally } \\
\text { defined fraction }\end{array}$ & Nominal target phase & experimental condition \\
\hline step 1 & $0.11 \mathrm{~mol} / \mathrm{L} \mathrm{CH} \mathrm{CH}_{3} \mathrm{COOH}$ & exchangeable & $\begin{array}{l}\text { soluble and exchangeable } \\
\text { cations and carbonates }\end{array}$ & \multirow{4}{*}{$\begin{array}{l}\text { room temperature, constant } \\
\text { shaking } 16 \mathrm{~h} \\
\text { room temperature, constant } \\
\text { shaking } 16 \mathrm{~h} \\
\text { room temperature } 1 \mathrm{~h} \text {, occasional } \\
\text { shaking, then agitation } 85^{\circ} \mathrm{C}, 1 \mathrm{~h} \\
\text { room temperature, constant } \\
\text { shaking } 16 \mathrm{~h} \\
\text { room temperature, constant } \\
\text { shaking } 16 \mathrm{~h}\end{array}$} \\
\hline step 2 & $0.5 \mathrm{~mol} / \mathrm{L} \mathrm{NH} \mathrm{N}_{2} \mathrm{OH} . \mathrm{HCl}$ at $\mathrm{pH} 1.5$ & reducible & Fe-Mn oxyhydroxides & \\
\hline step 3 & $\begin{array}{l}\mathrm{H}_{2} \mathrm{O}_{2}\left(85^{\circ} \mathrm{C}\right) \text { then } 1.0 \mathrm{~mol} / \mathrm{L} \\
\mathrm{CH}_{3} \mathrm{COONH}_{4}\end{array}$ & oxidisable & organic matter and sulfides & \\
\hline step 4 & aqua regia & residual & & \\
\hline
\end{tabular}

average weight $0.02 \mathrm{~g}$ ). Measurements were calibrated with at least 5 reference materials (USGS Mn Nodule A1, USGS Marine mud MAG-1, USGS jasperoid GXR1, IAEA lake sediment SL1 and IAEA Soil-7) and sample analysis was done in duplicate to compensate for possible sample heterogeneity. Particulate organic carbon (POC) and nitrogen (PON) contents were measured in $0.25 \mathrm{mg}$ samples previously decarbonated by $3.4 \mathrm{~mL}$ of $1 \mathrm{~N} \mathrm{HCl}$. Decarbonation comprises of 4 cycles of addition of $\mathrm{HCl}$ solution, $20 \mathrm{mn}$ of $300 \mathrm{rpm}$ orbital shaking, $3000 \mathrm{rpm}$ centrifugation, solution separation. Samples were weighed precisely and analysed through a Carbon Hydrogen and Nitrogen (CHN) analyser (Thermoflash EA 1112 series).

\section{Enrichment factors}

Enrichment factors (EF) were calculated by normalizing concentrations to $\mathrm{Al}$ and using local background values established for the Seine river watershed by (Thévenot et al., 2002) through measurements of selected river mouth values based on an $\mathrm{Al}$ content of $33000 \mathrm{mg} / \mathrm{kg}$. Assembled background values are shown on Table 2 and formulae is shown in Equation 1. The EF values should be evaluated keeping in mind the shortcomings of this approach (Reimann and de Caritat, 2005; Karbassi et al., 2008). Here, local background values were preferred to continental crust concentrations, due to the specificity of the carbonaceous Seine River basin geology.

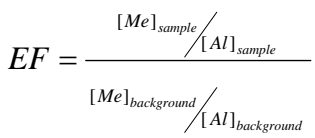

Where EF where $[\mathrm{Me}]_{\text {sample }}=$ metal concentration in sample, $[\mathrm{Al}]_{\text {sample }}=$ aluminum concentration in sample,
$[\mathrm{Me}]_{\text {background }}=$ metal concentration in background value and $[\mathrm{Al}]_{\text {background }}=$ aluminum concentration in sample.

\section{Scanning electron microscopy analyses}

Cartography of suspended sediment were collected at $6-7 \mathrm{kV}$ using in backscattered electrons imaging mode on a Zeiss ULTRA scanning electron microscopy (SEM) coupled with field emission gun (FEG) at the IMPMC, Paris, France. Energy Dispersive X-ray Spectroscopy (EDXS) data were collected at the same electron beamvoltage using a BRUKER AXS Si-drift detector. A supplementary image coupled with its EDS spectrum is also demonstrated. This latter image was obtained with JEOL JSM 840 SEM coupled to an X-ray microanalysis system from Princeton Gamma Tech (PGT) at LSCE.

\section{RESULTS AND DISCUSSION}

Extraction recoveries, analytical uncertainties and limit of detection

Extraction and analytical processes were validated using various standard materials. Extraction recovery (recovery in Table 4) was calculated by comparing the average concentration of our BCR sequential extraction on $0.25 \mathrm{~g}(\mathrm{n}=4)$ with the BCR certified values comprising of $\mathrm{Zn}$, Cd, $\mathrm{Pb}, \mathrm{Cr}, \mathrm{Ni}$ and $\mathrm{Cu}$ in the exchangeable, reducible and oxidisable fraction. Recovery value is accompanied with standard deviation (SD in Table 4). Analytical detection limits (DL in Table 4) are two times the blank value of sample that went to the same preparation, extraction, and analytical treatment. Speciation values were also validated by comparing the sum of the 4 extracted fractions with 
Table 2: Background concentration (mg/kg) in selected river mouth values (Poses estuary) established by Thévenot et al. (2002)

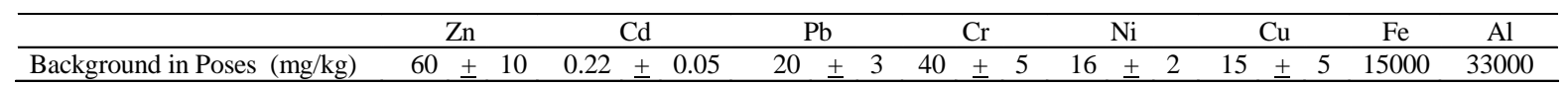

Table 3: Concentration of average major element contents of suspended particulate matter collected monthly in the sediment trap from December 2008 to August $2009(n=7)$

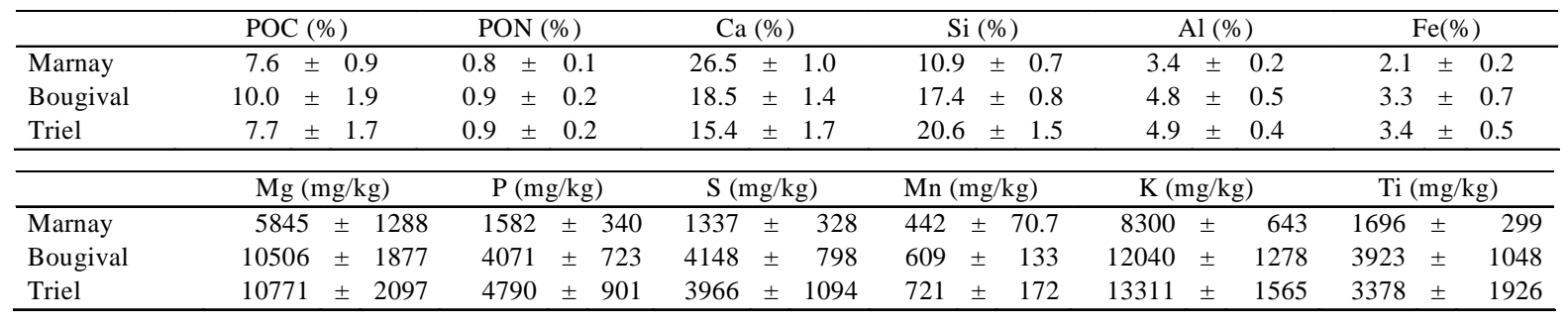

Table 4: Average recovery and its standard deviation (Recovery and SD in \%) of BCR sequential extraction in this study performed on the BCR-701 sediment compared with concentration of trace elements, certified by the BCR ( $\mathrm{n}=4)$. Analytical detection limits (DL in $\mathrm{mg} / \mathrm{kg}$ ) are calculated through 2 times the average blank values.

\begin{tabular}{|c|c|c|c|c|c|c|c|c|c|c|c|c|c|c|c|c|c|c|}
\hline & \multicolumn{3}{|c|}{$\mathrm{Zn}$} & \multicolumn{3}{|c|}{$\mathrm{Cd}$} & \multicolumn{3}{|c|}{$\mathrm{Pb}$} & \multicolumn{3}{|c|}{$\mathrm{Cr}$} & \multicolumn{3}{|c|}{$\mathrm{Ni}$} & \multicolumn{3}{|c|}{$\mathrm{Cu}$} \\
\hline \multirow[b]{2}{*}{ Exchangeable fraction } & & ery \pm SD & D DL & recov & ery_SD & DL & recove & ery_SD & DL & recov & $\mathrm{ry} \pm \mathrm{SD}$ & DL & recov & ery_SD & DL & recove & ery \pm SD & D DL \\
\hline & 98 & \pm & 0.5 & 104 & \pm & 53 & 121 & \pm 7 & 3.7 & 118 & \pm 9 & 32 & 95 & \pm 9 & 0.5 & 115 & \pm 5 & 520 \\
\hline Reducible fraction & 93 & \pm & 8904 & 82 & \pm & 26 & 99 & 2 & 46 & 91 & \pm & 394 & 96 & 7 & 208 & 92 & \pm & 714 \\
\hline Oxidisable fraction & 82 & 11 & 1368 & 86 & \pm 26 & 185 & 58 & \pm 23 & 53 & 90 & \pm & 115 & 81 & 10 & 100 & 81 & \pm & 75 \\
\hline
\end{tabular}

Table 5: Average recovery and standard deviation (Recovery SD in \%). Recovery compares the total extracted metals in the four fractions with the BCR sequential extraction procedure compared to metal concentration obtained by total digestion $(n=7)$

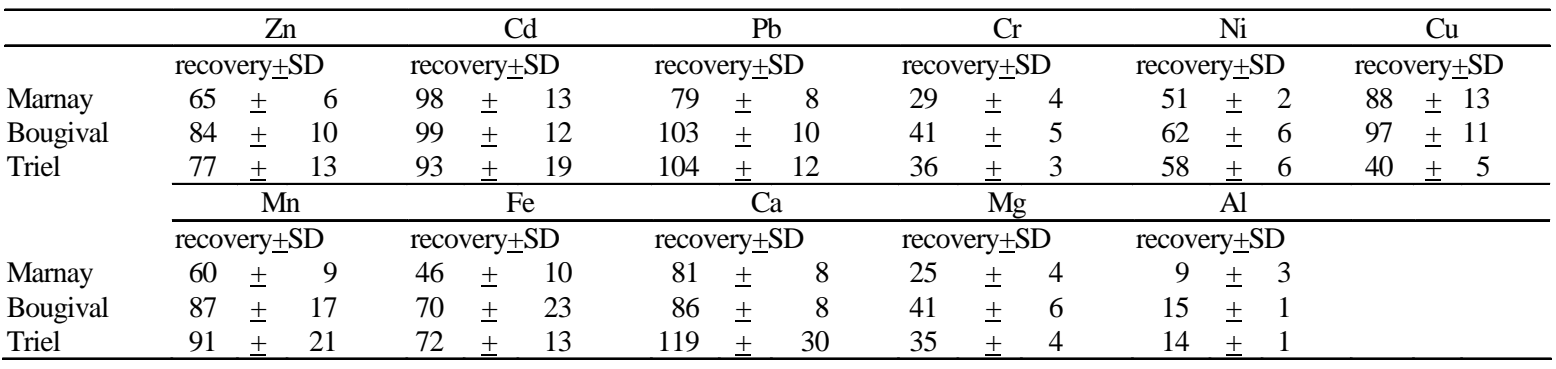

the total digestion results (Table 5). For the trace elements, SD values showed that $\mathrm{Cd}$ and $\mathrm{Cu}$ shows a low reproducibility with SD ranging from $13-19 \%$ for Cd and 13-16 \% for $\mathrm{Cu}$. Cd concentrations are relatively low, which may be prone to contamination during the extraction. This is reflected in our recovery levels which are higher than total digestion values in downstream sites, 99+12 and 93+19 at Bougival and Triel, respectively. Ca presented difficulties as it is present in extremely high quantity in the exchangeable fraction and may often pose difficult analytical problems.
Nevertheless, the recovery level between the 4 extraction phases of the BCR and our total bulk extraction depends on the metal's properties and the site's location. For most cases, more than $90 \%$ of Cd and $\mathrm{Pb}$ are extracted by the BCR extraction, except for $\mathrm{Pb}$ in Marnay which has a slightly lower recovery, at 79+7 \%. More than $80 \%$ of $\mathrm{Cu}$, Zn, and Ca are extracted with the BCR sequential extraction except for $\mathrm{Zn}$ at Marnay where recovery compared to the total digestion is relatively lower, $65+6 \%$. Zn, $\mathrm{Pb}, \mathrm{Cr}$, Ni and $\mathrm{Al}$ extracted by the BCR are significantly higher at Bougival than at Marnay. This shows that $\mathrm{Zn}, \mathrm{Pb}, \mathrm{Cr}$, and Ni could be 
from natural sources, associated to $\mathrm{Al}$ which would be more resistant to chemical extraction. $\mathrm{Cr}$ and $\mathrm{Ni}$ are probably found in the crystalline phases because they are only half extracted by the BCR extraction, $52+2,62+6$, $58+5$ for $\mathrm{Ni}$, and even lower for $\mathrm{Cr} 29+341+537+3$ at Marnay, Bougival and Triel, respectively. For $\mathrm{Cd}, \mathrm{Cr}, \mathrm{Cu}$, $\mathrm{Ni}, \mathrm{Pb}$ and $\mathrm{Zn}$, these results agree with most studies using the BCR sequential extraction, although none specified the uncertainty and detection limits for each extraction phase and each element. Larner et al. (2008) stated an extraction efficiency of 70-115\%. Nevertheless, these values were incomparable with those from other studies because our total digestion protocol attacks almost $100 \%$ of the bulk sediment. Our recovery would then be underestimated compared to recoveries values in other studies where pseudo-total digestion were performed (i.e. Larner et al., 2008). The major elements showed different extractability by the BCR extraction compared to the total bulk digestion, reflecting the different mineral forms in which the major element take form. The order of extractability from the element less extracted by the BCR to the most extracted is $\mathrm{Al}<\mathrm{Mg}<$ $\mathrm{Fe}<\mathrm{Mn}<\mathrm{Ca}$.

\section{Enrichment factors}

Enrichment factors (EF) of the 7 values at each site were averaged and shown on Fig. 3. Values showed significant increase in downstream samples for $\mathrm{Zn}, \mathrm{Cd}$, $\mathrm{Pb}$ and $\mathrm{Cu}$. On the other hand, $\mathrm{Cr}$ and $\mathrm{Ni}$ show no spatial increase in EF, keeping a relatively steady value of around 2 from Marnay to Bougival and Triel. These two

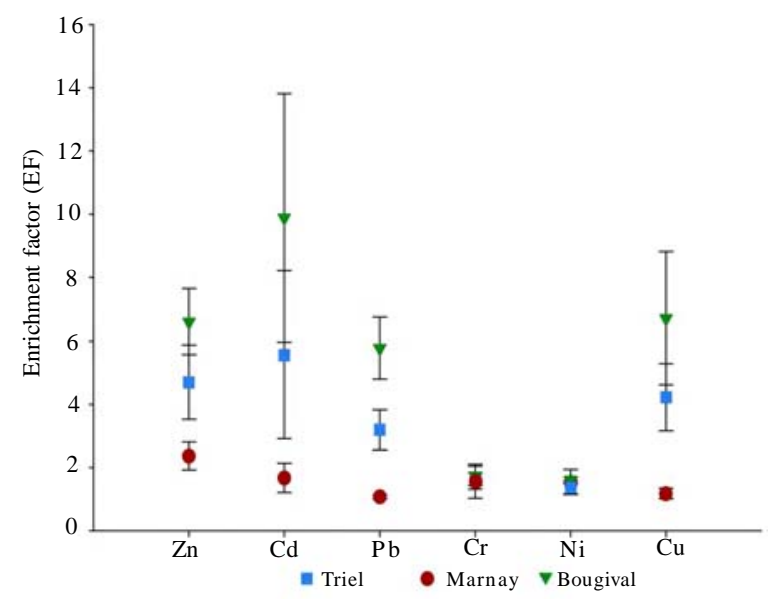

Fig. 3: Average enrichment factors during December 2008 until August 2009 for six metals (Cd, Cu, Cr, Ni, Pb, Zn) at the 3 studied sites (Marnay, Bougival, Triel) $n=7$ elements represent metals with the solid phase nonenriched by urban activities. In the case of the Seine River, the evolution of the concentration of the trace elements is also accompanied by an increase in most of the major elements (Table 3). The trend of metal enrichment in suspended sediments is similar with recent studies of metals in the Seine River through analysis of sediment cores and estuarine mussels (Meybeck et al., 2007; Le Cloarec et al., 2009). This shows that SPM collected in this study are representative to the Seine watershed and that these four metals represent metals affected by anthropogenic sources. Urban activities may increase EF in two or even seven folds in the downstream sites, depending on the metals. In average, $\mathrm{Cd}$ is the metal most enriched while $\mathrm{Zn}, \mathrm{Pb}$ and $\mathrm{Cu}$ present $\mathrm{EF}$ of 6-7. Metal concentrations at Bougival were not found to be lower than at Triel (Mann-Whitney, $\mathrm{p}=0.983$ ), despite of the Seine Aval WWTP outlet situated between the two sites. Considering the possible contribution of the WWTP outgoing flow to the metal contamination in the water column, one could have expected that metal concentrations in SPM would be higher at Triel than at Bougival. In 2002, Thévenot et al. (2002) calculated that particulate flux of $\mathrm{Cd}, \mathrm{Cu}$ and $\mathrm{Pb}$ from the Seine-Aval WWTP contributed from 2-6\% in the river mouth despite of the relatively low SPM concentration in the WWTP outlet water of 28-49 mg/L ((Estebe et al., 1998; Meybeck et al., 1998; Thévenot et al., 2007). Through calculations of influx, WWTP treatment efficiency and sludge recovery, Thévenot et al. (2007) established an outflux of 26, 25.5 and 90 t. $\mathrm{y}^{-1}$ for $\mathrm{Cu}, \mathrm{Pb}$, and $\mathrm{Zn}$ respectively. Buzier et al., (2006) also found that WWTP outflux may have a significant impact on the labile metal flux downstream of the outlet in low flow conditions. Ever since these studies were published, an effort was made through construction of numerous WWTP to distribute and relieve the wastewater load of Seine Aval. This finding indicates that improved WWTP are efficient in reducing incoming metal load to the Seine River. The analysis of the major elements is an important aspect in the interpretation of sequential extraction data as these major phases are likely to be the carrier phase of the trace elements. In order to confirm whether our extraction corresponds to the operationally-defined fraction, the extracted major elements for each step are presented (Fig. 4). At Bougival and Triel, Ca is more than $90 \%$ extracted on the exchangeable fraction, leaving less than $10 \%$ extracted in the reducible step and almost no Ca is found in the oxidisable and residual 
phase. Upstream, the Seine shows a slightly different behaviour where more $\mathrm{Ca}$ is found in the reducible fraction. Unlike $\mathrm{Ca}, \mathrm{Fe}$ and $\mathrm{Al}$ that varies between the three sites, there is no significant difference in the distribution of $\mathrm{Mg}$ and $\mathrm{Mn}$ at the three sites. Mn takes on a slightly similar behaviour to $\mathrm{Ca}$ where around 70 $\%$ are found in the exchangeable form while $\mathrm{Mg}$ contains more oxidisable and residual form. Even though $\mathrm{Fe}$ and Mn exist as oxides, the distribution of the two elements is significantly different. Fe is not released in the exchangeable fraction but rather during reducible and residual extraction for Bougival and Triel and mostly in the residual fraction for Marnay. The domination of $\mathrm{Ca}$ at Marnay with an average of $26.5 \%$ reflects the geological condition of the Seine watershed where $95 \%$ being underlain by carbonate rocks (Meybeck et al., 1999). Further downstream, Ca concentration decreases to an average of $18.5 \%$ and $15.4 \%$ for Bougival and Triel, respectively, and replaced by the general increase of other major elements such as $\mathrm{Si}$, Fe, Mg, P, S, Mn, K and Ti. For example, Si concentration increases from $10.9 \%$ at Marnay to $17.4 \%$ and $20.6 \%, \mathrm{Fe}$ average concentration increases from $2.1 \%$ to $3.3 \%$ in the downstream sites. A dramatic increase is observed for $\mathrm{P}$ and $\mathrm{S}$ concentrations at Bougival and Triel compared to Marnay. The impacts of anthropogenic activities on $\mathrm{P}$ and $\mathrm{S}$ are less well documented but some studies mentioned sources mostly coming from wastewater (Houhou et al., 2009). The increase of $\mathrm{P}$ and $\mathrm{S}$ maybe due to the increase of organic matter. Even though on the average, there is no significant difference between POC at Marnay, Bougival and Triel, but on a monthly basis, Bougival contains higher POC than Marnay and Triel (Mann Whitney Test for 7 months of samples $\alpha=0.05$ ).
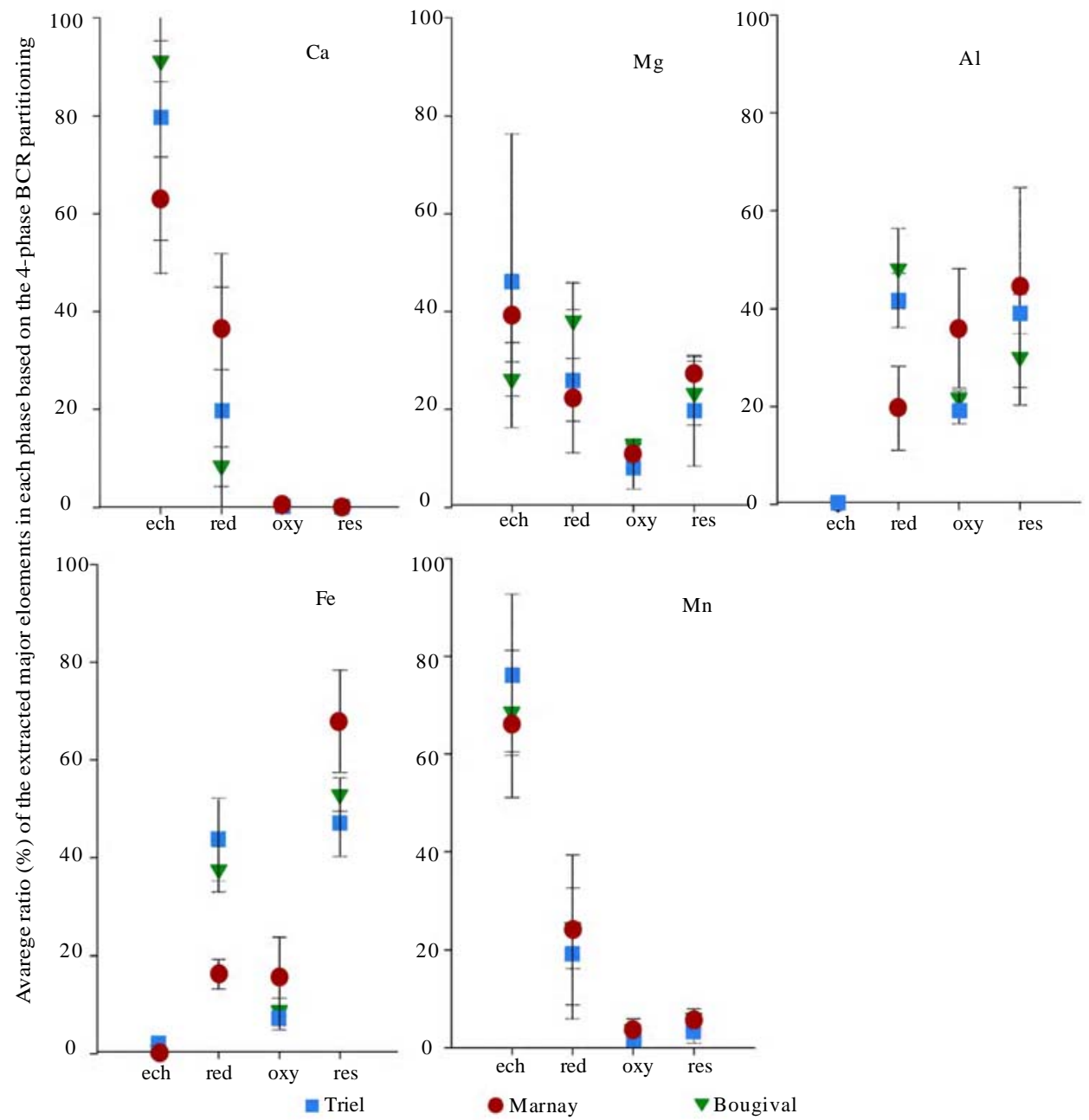

Fig. 4 : Average ratios of extracted major elements for each BCR sequential extraction phase at the 3 sites (Marnay, Bougival, Triel) (n=7) 
Nevertheless, it is also possible that $\mathrm{P}$ and $\mathrm{S}$ increase is due to increasing phosphate, sulfate or sulfide species. The evolution of $\mathrm{Al}$ concentrations in the 3 sites underlines the importance of also interpreting data normalized with Al through enrichment factor.

\section{Speciation}

The average distribution for the 7 monthly sampling of the 6 metals is shown in Fig. 5. The distribution is different for each metal and site. Detailed speciation of the environmentally relevant trace metals are presented in Fig. 6. Sediment traps integrate one month of SPM during which the sample may be subjected to evolution of speciation. In the course of a month, SPM sedimenting on the bottom of sediment trap may create reducing conditions, favourizing the oxidation of organic matter and the formation of reduced forms. This possibility is to be taken into account during the lecture and interpretation of data. A spatial evolution in the $\mathrm{Al}$ speciation is also observable mostly for the reducible phase. This evolution of Al would mean that there is an increase of allochthonous $\mathrm{Al}$ coming from the Greater Paris Region. This is also the case for Fe where the reducible proportion increases in the downstream sites. The similarity of Fe and Al where both elements tend to be present mostly in the reducible fraction at Bougival and Triel may mean a similar anthropogenic source. Indeed, Fe and $\mathrm{Al}$ are the two most abundant metals (Luoma and Rainbow, 2008) thus becoming the two mostly utilized metals worldwide (USGS, 2010). In 2004, 1370 kt of Al were used in France, mostly in the transportation, construction and packaging sector (AFA). Nevertheless, this anthropogenic Al possibly present in the reducible fraction only accounts for $30-40 \%$ of total BCR extractable Al (Fig. 4), which in turn only contributes to $14-15 \%$ of the total Al in Seine SPM(Online Resource Table 2). This small proportion of reducible and possibly anthropogenic $\mathrm{Al}$ would only be around $6 \%$ of the total $\mathrm{Al}$ and with this uncertainty it is still considered safe to calculate enrichment factors through normalization by $\mathrm{Al}$. As a whole, an evolution from upstream to downstream is significant enough while the difference between Bougival and Triel is less pronounced (Mann Whitney, p= 59\%, 49\% 85\% between Marnay to Bougival, Marnay to Triel and Bougival and Triel, respectively, with $\mathrm{H}_{0}$ hypothesis is proportion ${ }_{\text {site } 1}=$ proportion ${ }_{\text {site } 2}$ ). Regarding temporal variation, the distribution at a given site is relatively stable with deviation of around $5 \%$ for most metal in certain fractions $(n=7)$, and with a maximum of $10-15 \%$ for some metals.
Speciation evolution from Marnay to Bougival and Triel was observed for $\mathrm{Zn}, \mathrm{Cd}, \mathrm{Pb}$ and $\mathrm{Cu}$ but not for $\mathrm{Cr}$ and $\mathrm{Ni}$. Moreover, these four metals are those demonstrating a significantly higher EF downstream. This implicates that anthropogenic contamination is likely to bring in material with different metal distribution and that variation in the physico-chemical condition downstream leads to a different type of speciation. The general observation allows us to divide the six metals into 2 distinct groups. The first group constituting of $\mathrm{Zn}, \mathrm{Cd}$, and $\mathrm{Pb}$, averages more than $60 \%$ in the reducible fraction and even reaching up to $90 \%$. The reducible fraction for these three elements is always significantly higher than the 3 other fractions ( $t$ test, $\alpha=0.05)$. These metals are known to be preferably associated with iron oxy-hydroxides (Luoma and Bryan, 1981) which would explain the high proportion found in the reducible fraction. The increasing proportion of these reducible metals rises significantly from upstream to downstream, marking a possible anthropogenic impact. This idea is also supported with the increasing EF as the water reaches Bougival and Triel. The increase in EF is accompanied with the increase in the reducible fraction for $\mathrm{Zn}, \mathrm{Pb}$ and $\mathrm{Cu}$ but in a lesser extent for $\mathrm{Cd}$ which shows that for this metal, the metal physico-chemical properties also play an important role in determining the distribution. The second group consists of $\mathrm{Cr}, \mathrm{Ni}$, and $\mathrm{Cu}$ with higher fractions of the residual phase than the first group, averaging around $35 \%$. Compared to the first group, the metals in the second group are distributed relatively equal where no fraction holds more than 60 $\%$ for a given metal, except for residual Cu at Marnay. While in a first approach, the metals can be divided into two groups, each metal shows a typically different behaviour and it will be interesting to discuss the distribution of each particular metal. From the first group, $\mathrm{Zn}$ seems to stand out from $\mathrm{Cd}$ and $\mathrm{Pb}$ in terms of association to the exchangeable fraction (Fig. 5). The proportion of $\mathrm{Zn}$ associated to this phase remains around $20 \%$ from Marnay to Triel. Despite the stability in its proportion, this means an increase of 4-6 folds in concentration going from an average of $9 \mathrm{mg} / \mathrm{kg}$ at Marnay to an average of 63 and $45 \mathrm{mg} / \mathrm{kg}$ at Bougival and Triel respectively. Moreover, the relative stability of the proportion of $\mathrm{Zn}$ associated to the exchangeable phase is seen in a smaller proportion for oxidisable $\mathrm{Zn}$. The proportion remains around $10 \%$ while the concentration increases 2-4 folds in most cases. Except for July 2009, the average proportion of exchangeable and oxidisable $\mathrm{Zn}$ is relatively stable from Marnay to 

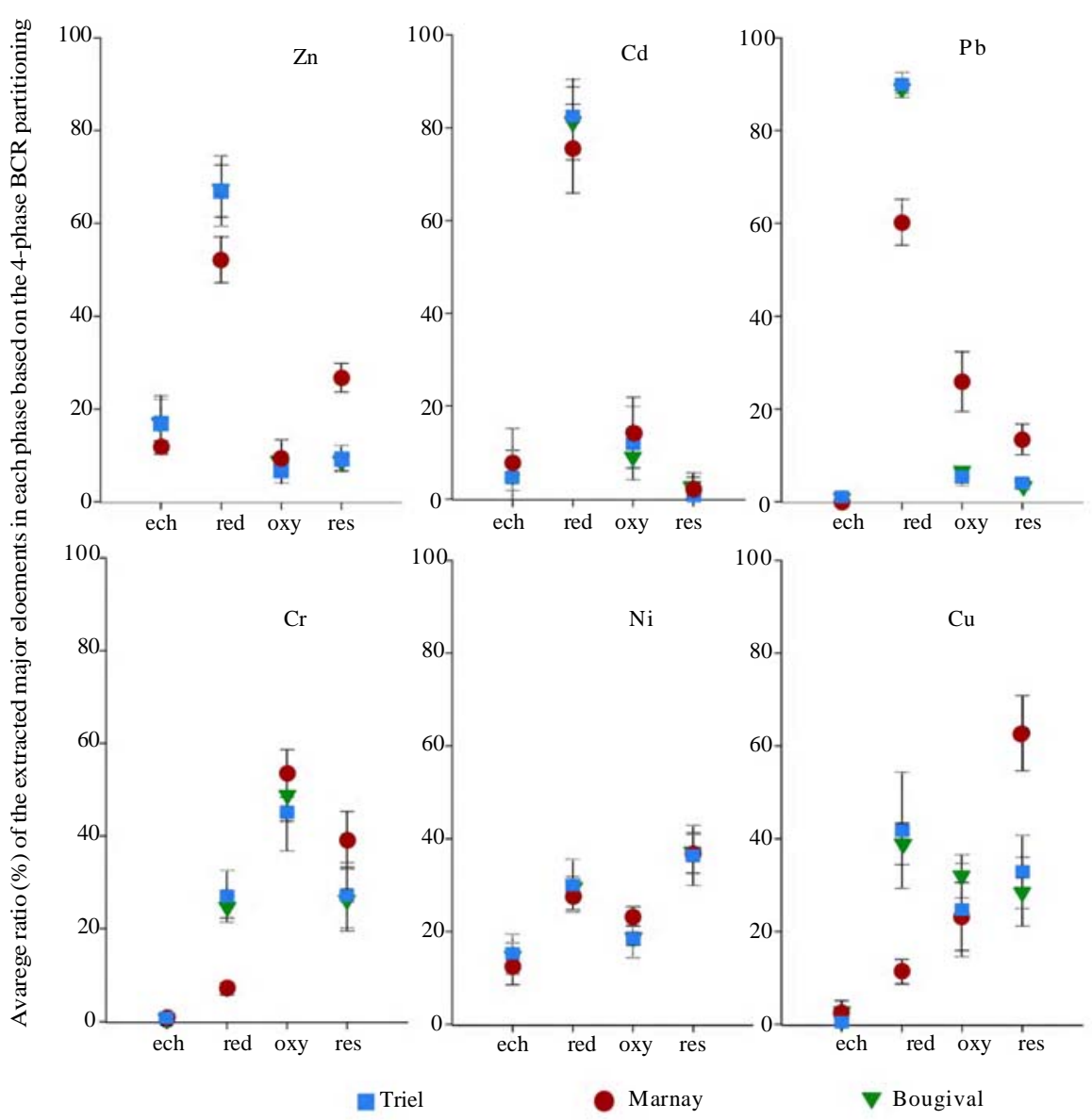

Fig. 5 : Average ratios of extracted trace elements for each BCR sequential extraction phase of the 3 sites (Marnay, Bougival, Triel) (n=7)

Triel. Distinct changes are observable with Zn associated to the reducible phase (student test confidence interval $99 \%$ between Marnay and the two downstream sites). Average reducible $\mathrm{Zn}$ increased from upstream to downstream with $52+9 \%$ at Marnay to $67+6 \%$ at Bougival and $67+8 \%$ at Triel. This is the result of a 4 to 7 time increase of concentration from Marnay to Bougival and Triel. Consequently, the reducible fraction accounts for at least $50 \%$ of BCR extractable $\mathrm{Zn}$ at Marnay and up to $75 \%$ for Bougival and Triel. Garnaud et al. (1999) also found a majority of reducible and exchangeable Zn particularly in SPM sampled during a rain period in the le Marais catchment outlet of the Seine River. A weak increase of $\mathrm{Zn}$ in the residual form from upstream to downstream also marks a relatively steady amount of residual $\mathrm{Zn}$ transported in the Seine River which could originate from the Seine's geological background. It is difficult to compare Seine
Zn distribution with other urban river studies because $\mathrm{Zn}$ in the Seine river watershed is particular compared to other urban rivers in the world. Unlike most watersheds, roof runoff constitutes one of the major sources of Zn contamination in the Greater Paris Region, where it reaches roughly $40 \%$ of all roofing surfaces (Robert-Sainte et al., 2009). 85-100 \% of Zn washed from roof surfaces are in its ionic form (Heijerick et al., 2002). Zn has a high affinity for solid particles and so it is easily adsorbed mostly to carbonates, hydrous iron oxide and silicate minerals (Fujiyoshi et al., 1994). Nevertheless, these Zn-bearing particles undergo physico-chemical evolution and once found in the sewer system, $70 \%$ of $\mathrm{Zn}$ is found to be associated with organic matter and biofilm (Rocher et al., 2004). However, our analysis showed that $\mathrm{Zn}$ in the SPM is far more likely to be associated with the reducible form, with an average of more than two thirds of the total 


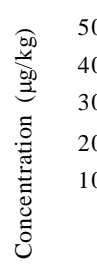
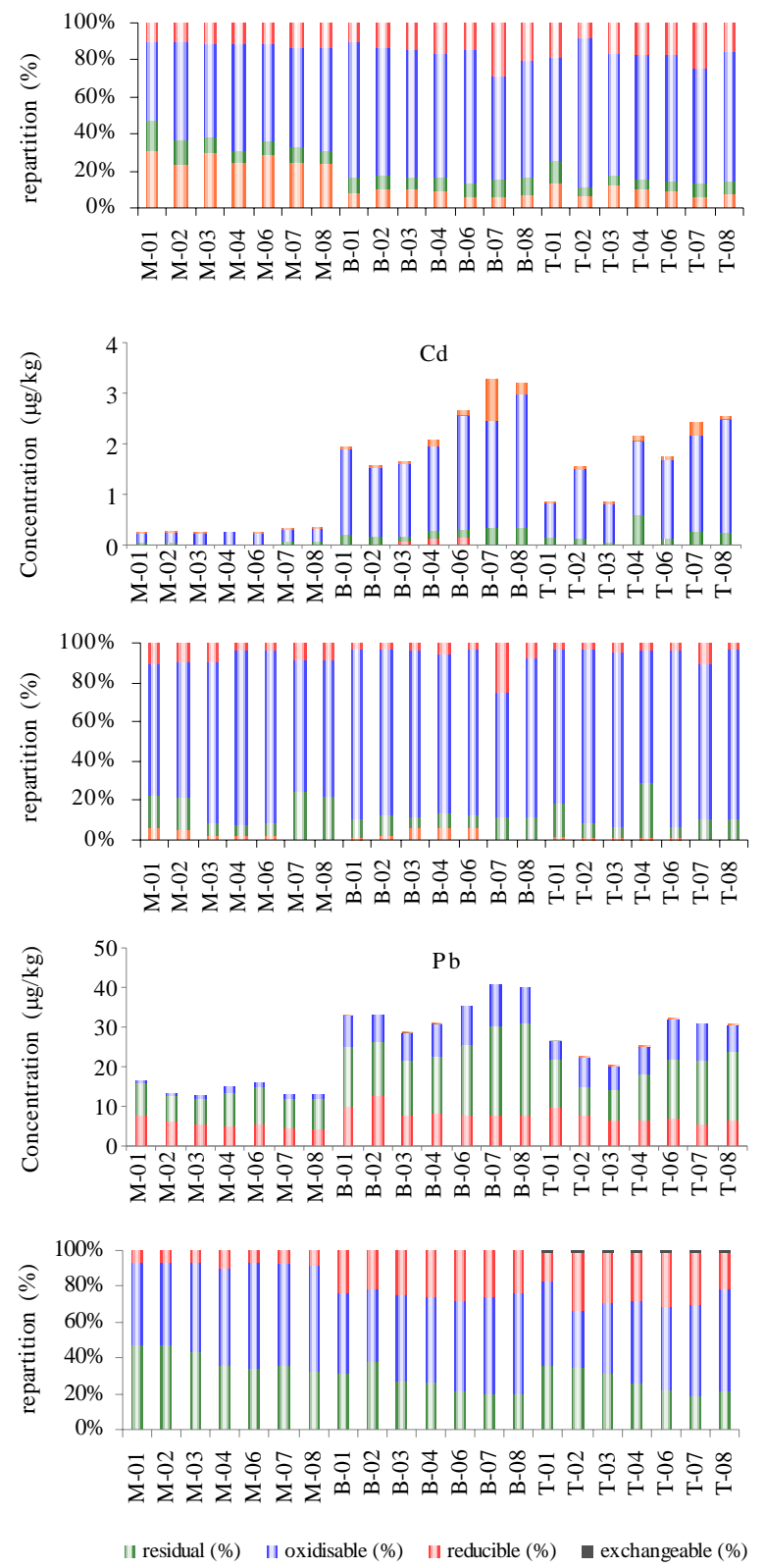
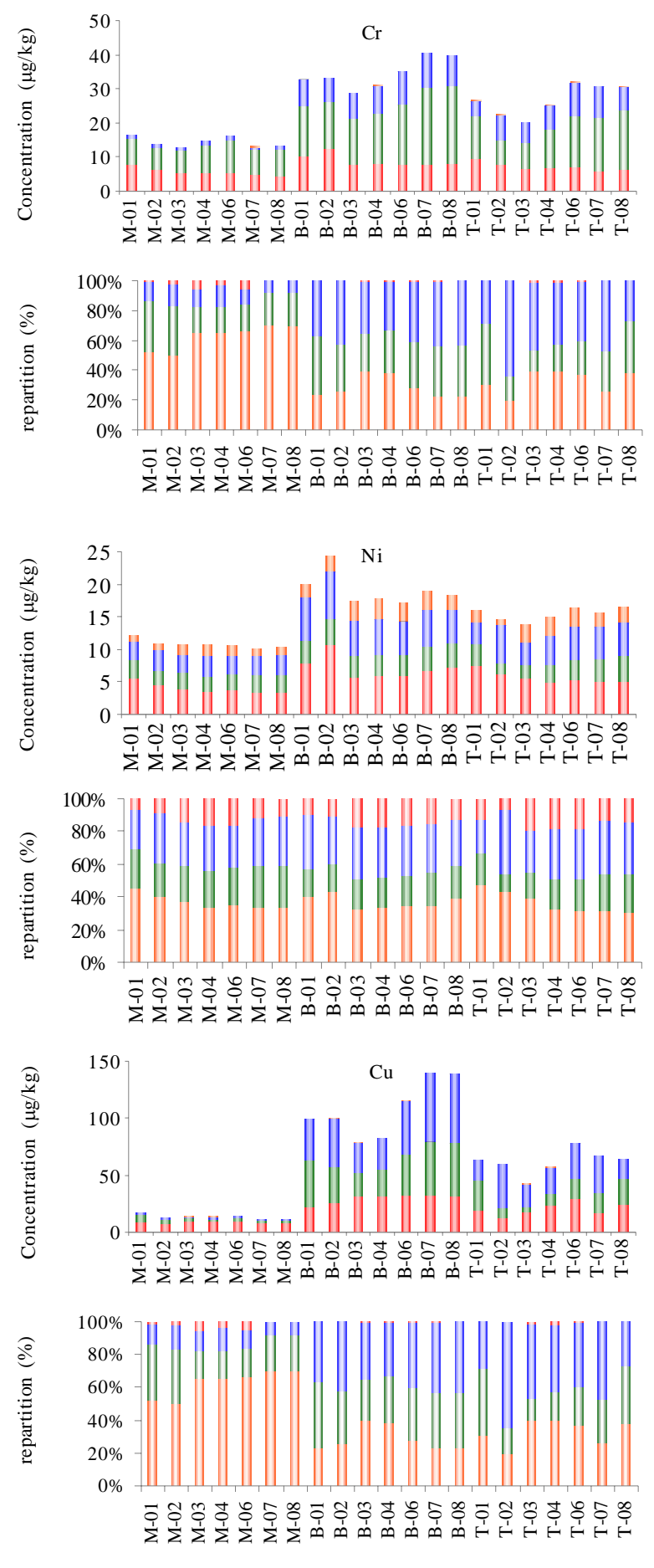

|| residual (\%) || oxidisable (\%) $\mid$ reducible (\%) $\mid 1$ exchangeable (\%)

Fig. 6 : Distribution of $\mathrm{Zn}, \mathrm{Cd}, \mathrm{Pb}, \mathrm{Cr}, \mathrm{Ni}$, and $\mathrm{Cu}$ in the 4 different fractions of the BCR defined phases both in concentration (mg/ $\mathrm{kg}$ ) and relative concentration (\%) with axis X indicating $\mathrm{M}$ for Marnay, B for Bougival and $\mathrm{T}$ for Triel sites accompanied by numbers representing the month when the sediment trap was collected $(01=$ January 2009 until $08=$ August 2009)). 
BCR extractable Zn for Bougival and Triel. This means that the sediment undergoes further transformation until reaching the water body. Our result is comparable to the lower median percentage of acid-soluble $\mathrm{Zn}$ found in the urban streams of Prague (Hnatukova et al., 2009). The dominating reducible phase of $\mathrm{Zn}$ is to a further extent similar for $\mathrm{Cd}$. Cd is found to be associated up to $80 \%$ with the reducible phase increasing the concentration to 10 folds going from $200 \mu \mathrm{g} / \mathrm{kg}$ of Cd to around $2000 \mu \mathrm{g} / \mathrm{kg}$ from upstream to downstream. Although the relative distribution of the 4 phases remains relatively stable, the absolute concentration increases to 4-6 times from Marnay to Triel, and increasing more labile $\mathrm{Cd}$ in the exchangeable and reducible fraction simultaneously. The exchangeable proportion is higher in Bougival and Triel, in the 5-10 \% range. Nevertheless, along with $\mathrm{Zn}$ and Ni, Cd still represents one of the metals with the highest proportion associated to the exchangeable phase making it relatively more mobile to the environment than other metals, because the exchangeable phase is the phase most likely to go into the dissolved phase thus becoming more available to the environment. The high proportion of reducible Cd and Zn in the Seine River SPM differs from previous urban river studies which showed mostly acid-soluble fraction. Hnatukova et al., (2009) found 38-64 and 15-43 \% acid-soluble Cd and $\mathrm{Zn}$, respectively, in the urban streams of Prague as opposed to the acid-soluble $\mathrm{Cd}$ and $\mathrm{Zn}$ in Seine measuring at 3-11 \% and 8-28 \% respectively. This makes Cd one of the most mobile element compared to the 6 studied elements showing the highest proportion associated to the mobile phase (exchangeable+ reducible+ oxidisable), with an average of $2 \%$ associated to the residual phase. Comparing the six studied metals, Cd shows the highest EF increase from upstream to downstream, increasing 3 to 5 folds compared to an average EF increase of 2 to 3 folds for $\mathrm{Zn}$ and $\mathrm{Pb}$ in the downstream sites. This significant $\mathrm{Cd}$ increase in the bulk concentration is not accompanied with an evolution of the average distribution from upstream to downstream (Fig. 5). This is not the case for two urban watersheds, the St Lawrence River, Canada (Gagnon et al., 2009)and the Loura River, Spain (Filgueiras et al., 2004) which exhibited significant spatial variation of Cd solid speciation. Evolution for the Seine River solid SPM is only observable once comparing monthly variations when the proportion of exchangeable Cd along with exchangeable Zn increases in July 2009. This phenomenon could be attributed to the low flow occurring during the SPM accumulation for this sample (22 June to 22 July, 2009), illustrated in Fig. 2, but also the transport of first flush runoff from the storm rain taking place between the 16 and 17 July increasing the river flow rate from 126 to $189 \mathrm{~m}^{3} / \mathrm{s}$. This runoff discharge may consist of particles with different speciation as opposed to the low flow-particles which would explain the abrupt increase of exchangeable $\mathrm{Cd}$ and $\mathrm{Zn}$. The high EF of $\mathrm{Cd}$ and the relatively high proportion of $\mathrm{Cd}$ in the mobile fraction make $\mathrm{Cd}$ an important element to monitor in the environment. Nevertheless, despite of this high enrichment of the Cd downstream of the Seine River, Cd shows a stable distribution in the 4 fractions from upstream to downstream. The speciation of Cd found downstream is not similar to Cd speciation of solid matters collected in the basin such as traffic aerosols containing $75 \%$ of exchangeable Cd (Lebreton and Thevenot, 1992)or road dusts containing more than $30 \%$ of oxidisable Cd (Thévenot et al., 2002). This implies that urban Cd would be mobile and solid Cd entering the river would be directly remobilized to its preferable fractions in the solid phase, despite of its original form. This would make speciation-based source tracing in the solid form unadoptable for $\mathrm{Cd}$ in the Seine River. Pb showed the highest increase of the reducible fraction relative content from upstream to downstream (20-30\%) and a 10-15 fold the concentration increase. This is by far the highest spatial increase of the reducible fraction compared to $\mathrm{Zn}$ and Cd. Compared to $\mathrm{Zn}$ and Cd, there does not seem to be a significant proportion of exchangeable $\mathrm{Pb}$ compared to the four other fractions. In the downstream sites, the three remaining fractions, exchangeable, oxidisable and residual only makes up $10 \%$ of the total extractable $\mathrm{Pb}$. This means that further studies on $\mathrm{Pb}$ contamination has to be focused on the reducible fraction, containing mostly $\mathrm{Pb}$ associated with iron and manganese oxides. Nevertheless, our results remain similar to other studies of metal fractionation in urban watersheds. The preference of $\mathrm{Pb}$ for the reducible phase is also observed by Sutherland and Tack (2007) and Carter et al. (2006). They found a high association of $\mathrm{Pb}$ with the Mn oxide and to a lesser extent with the $\mathrm{Fe}$ oxide. Hnatukova et al. (2009) also found Pb to be mainly bound to the reducible fraction. Jain et al. (2008) also found only $1-3 \%$ of exchangeable $\mathrm{Pb}$ in the sediments of the River Narmada, India. The weak association of $\mathrm{Pb}$ with the exchangeable fraction is equally observed in 
the study by Carter et al. (2006). Nevertheless, the Seine oxidisable $\mathrm{Pb}$ proportion seems to be underestimated compared to their study as fractionation of $\mathrm{Pb}$ is mainly dominated by the reducible fraction. The study of Hassellov and von der Kammer (2008) strongly suggests that iron-oxide $\mathrm{Pb}$ bearing particles are in the form of nano-colloids. Consequently, $\mathrm{Pb}$ may be efficiently transported to the estuary. The Seine River is located in a carbonated basin. Consequently, SPM contains abundant carbonates onto which the metals could be adsorbed. Nevertheless, this is not the case for the Seine River where the absence of exchangeable $\mathrm{Cu}$, along with $\mathrm{Cr}$ and $\mathrm{Pb}$, is notably similar to the distribution in the Aire River (Carter et al., 2006). The predominant species in the range of $\mathrm{pH}$ of the Seine River measured during the campaign (between 7.5-8.3) would be $\mathrm{CuCO}_{3}(\mathrm{aq})$ and $\mathrm{Cu}\left(\mathrm{CO}_{3}\right)_{2}{ }^{2-}$ (Stumm and Morgan, 1981)which means that $\mathrm{CuCO}_{3}(\mathrm{~s})$ is not present even with abundant $\mathrm{CaCO}_{3}$ in the system. Along with $\mathrm{Zn}$, $\mathrm{Cu}$ seems to be the element with a mobile phase evolving considerably from upstream to downstream, where its proportion could reduce $20 \%$ the proportion of the residual phase. This would mean a higher mobility downstream, and it would also mean a high anthropogenic contribution. Similar to $\mathrm{Cd}, \mathrm{Ni}$ is distributed steadily from Marnay to Triel, around 15, 20, 30 , and $40 \%$ for the exchangeable, oxidisable, reducible and residual phases respectively. Ni displays a minimum spatial increase in absolute concentration from upstream to downstream, reflected by the values of Ni EF. These two evidences may mean that $\mathrm{Ni}$ sources mostly originate from lithogenic sources rather than anthropogenic contamination. Ni seems to be the metal containing in average the highest metal proportion in the residual fraction ranging around $31-47 \%$. The relatively steady proportion of the residual $\mathrm{Ni}$ from upstream to downstream would signify the steady contribution of lithogenic background, reflected by the steady values of enrichment factor from upstream to downstream. The relatively high exchangeable $\mathrm{Ni}$ is somehow comparable to that of Zn but while reducible and residual Zn varies considerably from upstream to downstream, reducible and residual Ni remain stable and do not show significant spatial variation. Therefore, the high exchangeable Ni cannot be contributed to anthropogenic sources, but more to the typical geochemistry of Ni to the solid phase. Among the elements found in the second group, $\mathrm{Ni}$ shows the highest exchangeable phase, which is not the case for other fractions. Similarly to $\mathrm{Cd}$ and $\mathrm{Zn}, \mathrm{Ni}$ is found to be already significantly associated with the exchangeable phase beginning from the upstream site. The presence of a significant exchangeable phase in $\mathrm{Ni}$, $\mathrm{Cd}$ and $\mathrm{Zn}$ is not at all apparent in $\mathrm{Pb}, \mathrm{Cr}$, and $\mathrm{Cu}$. The grouping of Ni, Cd, and Zn was observed by (TusseauVuillemin et al., 2005)on Seine River SPM. Based on a multi-elementary study, they found a correlation between the ratio of the dissolved and solid fraction $\left(\mathrm{K}_{\mathrm{d}}\right)$ of $\mathrm{Ni}, \mathrm{Cd}$ and $\mathrm{Zn}$. This would indicate similar adsorption-desorption behaviour for $\mathrm{Ni}, \mathrm{Cd}$ and $\mathrm{Zn}$. As mentioned above, a recent study observed a high variation of dissolved $\mathrm{Zn}$ in the Seine. $\mathrm{Zn}$ similar behaviour with $\mathrm{Ni}$ and $\mathrm{Cd}$ would imply that pulsating concentration of dissolved $\mathrm{Ni}$ and $\mathrm{Cd}$ could also be a problem in the Seine River. This should be further investigated as $\mathrm{Cd}$ and $\mathrm{Ni}$ are considered even a more toxic element and regulated by the European Water Directive. Similar to Ni, Cr displays a constant EF for the 3 sites. Nevertheless, what distinguishes $\mathrm{Cr}$ from $\mathrm{Ni}$ is that $\mathrm{Cr}$ seems to even be less mobile with relatively no exchangeable phase present. This is also supported by the low BCR-extractability of $\mathrm{Cr}$, representing more than $60 \%$ associated with the non-extractable phase indicated by the difference of the total $\mathrm{Cr}$ of the four BCR extracted fractions and the total Cr obtained by the bulk extraction. This would indicate as $\mathrm{Cr}$ being mostly incorporated in mineral particles, relatively difficult to extract. Chromite is regularly found in the Seine SPM through analysis by Scanning Electron Microscopy (SEM) (unpublished work) and this may be a possible mineral form of Cr. This is an evidence of the importance of completing total digestion with metal speciation study to understand its mobility to the environment. Compared to the 5 other elements, $\mathrm{Cr}$ seems to be an element that is mostly associated with the oxidisable phase, averaging about 40-50\%. The strong preference of $\mathrm{Cr}$ with organic matter was mostly observed in an anoxic estuary (Du Laing et al. 2009). The high capacity of Cr complexation with the organic matter is also observed in bed sediments (Lin and Chen, 1998). This would mean that $\mathrm{Cr}$ could be ingested by organisms consuming the organic matter. Despite the stable enrichment factor from upstream to downstream indicating possible lithogenic origin of $\mathrm{Cr}$, a shift of distribution, is apparent from Marnay towards Bougival and Triel. There is a $10 \%$ decrease of $\mathrm{Cr}$ in the residual phase, replaced by an increase in the reducible form. This shows that $\mathrm{Cr}$ evolves more considerably than $\mathrm{Ni}$ inside the solid phase and is more labile to physico-chemical changes. The abundance in the oxidisable phase is also apparent at a lesser extent for 
$\mathrm{Cu}$. The oxidisable $\mathrm{Cu}$ represents $30 \%$ as compared to $\mathrm{Cr}$ going up to $50 \%$. A concentration increase of 5-20 times is observed, the highest upstream-downstream increase of oxidisable $\mathrm{Cu}$ compared to other metals. Luoma and Rainbow (2008) noted the strong affinity of $\mathrm{Cu}$ to organic ligands. More recently, various studies in the Seine River also noted this characteristic which would be due to the presence of urban dissolved organic matter. It presents different complexing capacity as compared to the natural organic matter, thus creating a higher affinity for the dissolved copper (Pernet-Coudrier et al., 2008). Such colloidal organic matters could possibly be collected in a monthly trap. The formation of bio-film inside the trap could also be an equally important $\mathrm{Cu}$-collecting mechanism. As for $\mathrm{Zn}$ and $\mathrm{Pb}$, reducible $\mathrm{Cu}$ also shows an increase in proportion going from $12 \%$ at Marnay to $30-40 \%$ at Bougival and Triel. This abrupt apparition of reducible Cu could be attributed to a source related phenomenon where average EF increases 3-5 folds from Marnay to Bougival and Triel. $\mathrm{Cu}$ introduced to the river could be associated with the reducible fraction, especially the iron and Mn oxides. Luoma and Bryan (1981) noted Cu preference to iron oxy-hydroxides, although in our cases, the proportion of reducible $\mathrm{Cu}$ is relatively low as compared to reducible $\mathrm{Zn}, \mathrm{Cd}$ and $\mathrm{Pb}$ ranging about $40 \%$. A higher reducible fraction is observed at Triel on February 2009 where it reaches up to $70 \%$. This sudden increase of reducible $\mathrm{Cu}$ on February 2009 coincides with the increase of reducible $\mathrm{Zn}, \mathrm{Cd}$, and $\mathrm{Pb}$ for the same period. During this period, the Seine River flow rate at Bougival more than tripled in 11 days from 157 to $528 \mathrm{~m}^{3} / \mathrm{s}$. The flow decreased by an average of $200 \mathrm{~m}^{3} / \mathrm{s}$ during the next 9 days and re-increased to $505 \mathrm{~m}^{3} / \mathrm{s}$ in 7 days. These increasing flow rate episodes due to rain runoff would include urban runoff with specific source-related characteristics. As during this period, a significant increase in reducible $\mathrm{Zn}, \mathrm{Cd}, \mathrm{Pb}$ and $\mathrm{Cu}$ is observed, the 2 rain episodes were likely to transport urban pollutants associated in the reducible fraction, mostly iron oxides. Images of the Triel August 2008 suspended sediment sample using the SEM-FEG demonstrated iron oxide as a cluster with a geometrical crystal structure (Fig. 7a inset). The Ca detected behind the iron oxide cluster could indicate a calcite-hosted iron-oxide growth as suggested by the elemental cartography (Fig. 7a). The similar composition of iron oxide with Ca was also observed by SEM-EDS on bed sediment collected on 2001 (Tessier and Bonté, 2002). Iron oxide particles were found as cohesive particles and proved to be an effective metal scavenger (Hochella and White, 1990; Morin et al., 2009; Sekabira et al., 2010) found to be associated with $\mathrm{Cu}, \mathrm{Pb}, \mathrm{Sb}$ and $\mathrm{Zn}$.

\section{Sulfidic species}

The grouping of $\mathrm{Zn}, \mathrm{Cd}$, and $\mathrm{Pb}$ along with relatively mobile $\mathrm{Cu}$ would support the hypothesis of possible sulfidic forms in the samples. These four elements are known as chalcophile elements in the Geochemical Classification of Goldschmidt and preferably bond with sulphur rather than oxygen. Indeed, according to Larner et al. (2008), sequential extraction of samples containing sulfidic phases in oxic conditions would lead to redistribution of $\mathrm{Cd}, \mathrm{Zn}, \mathrm{Cu}$ and $\mathrm{Pb}$ to a lesser extent from the oxidisable to the reducible phase. This study explained that during the exchangeable extraction, sulfidic phases may be oxidised and redistributed to the reducible phase. No previous studies showed a significant amount of sulfidic phases in oxic riverine SPM non-affected by mining activities (Taylor and Owens, 2009). Therefore no special care was taken in preserving oxidation state during the sequential extraction procedure. This study showed that with the minor oxidisable phase, and the extremely high reducible fraction, a considerable amount of the studied metals could be associated with the sulfidic phases.

\section{Urban impacts on metal speciation}

The proportion of the reducible fraction seems to reflect the enrichment factor of the metal. Metals affected by anthropogenic activities having a relatively high enrichment factor $(E F>3)$, seems to prefer association with the reducible form. Obviously, the proportion of the residual fraction reflects the contribution of the background. The oxidisable fraction also seems to show, to a lesser extent, contribution by natural sources as it is exceptionally high for $\mathrm{Cr}$, reaching up to $50 \%$ compared to the other fractions. $\mathrm{Ni}$, a non-enriched metal in the Seine River, also contains a relatively high oxidisable fraction, ranging around $23 \%$ at Marnay, and $11-23 \%$ at the downstream sites. It seems that the immediate mobility is minimized for most of the metals, reflected by their small proportion in the exchangeable form. Two downstream sites were chosen in order to measure impacts of Greater Paris at Bougival and of the wastewater treatment plant (WWTP) Seine Aval at Triel. Even though at Bougival the metal concentrations are 

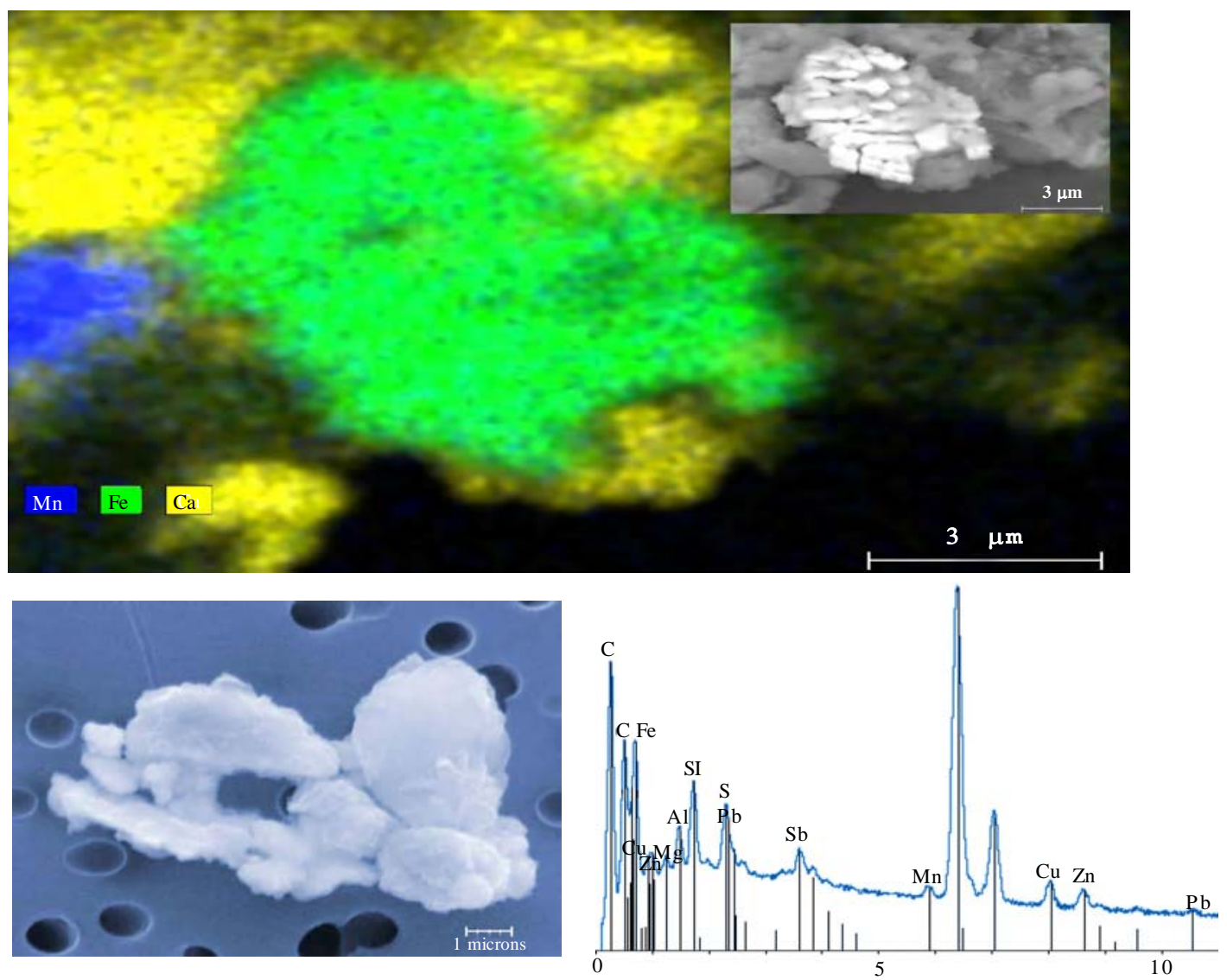

Fig. 7: (a) Cartography from energy dispersive spectroscopy (EDS) and Scanning electron microscopic image (inset) and of ironmanganese oxide growth on calcium carbonate mineral analyzed with MEB-FEG at IMPMC, Paris ; Bottom : SEM image (b) and EDS spectrum (c) of a cluster of particles indication metal bearing iron oxide associated with antimony, copper, lead, and zinc analyzed with MEB-EDS at LSCE, Gif sur Yvette

significantlyhigher than at Triel, no significant difference is remarkable in their distribution between the four phases for any of the six metals. The addition of numerous WWTP and the redistribution of incoming wastewater to other plants in the course of the Seine River may prove to be effective in reducing the metal load flowing in the Seine River at Bougival. Nevertheless, the issue of reducing the metal load is still important for Greater Paris where enrichment from Marnay to Bougival remains considerably high.

\section{CONCLUSION}

In this study, applying the BCR sequential extraction to suspended particulate matter sampled monthly in the Seine River, a river impacted by human activities, the highly urban Greater Paris Region is found to modify not only metal concentration but also metal speciation as observed in speciation evolution between Marnay vs Bougival and Triel. As $\mathrm{Cd}, \mathrm{Cu}, \mathrm{Pb}$ and $\mathrm{Zn}$ are enriched in the suspended matter, their reducible fraction is found to greatly increase. Based on the speciation behaviour, the analysed metals can be divided into two groups; the first group contains the anthropogenic metals, $\mathrm{Cd}, \mathrm{Pb}$, and $\mathrm{Zn}$, in which the reducible fraction accounts for more than $60 \%$ of the total BCR extractable metals for the downstream Paris sites. The second group includes $\mathrm{Cr}, \mathrm{Cu}$, and $\mathrm{Ni}$ that are associated with at least $15 \%$ in three of the four defined BCR fraction in the downstream Paris sites. Exchangeable fraction is only significant for $\mathrm{Cd}, \mathrm{Ni}$ and $\mathrm{Zn}$ while the oxidisable fraction accounts for less than $20 \%$ for the anthropogenic metals downstream except for $\mathrm{Cu}$. The enrichment of $\mathrm{Zn}, \mathrm{Pb}$ and $\mathrm{Cu}$ by the Greater Paris Region seen at Bougival and Triel is accompanied by the increasing distribution of metals on more mobile phases including the exchangeable and reducible phases. This 
fraction is more mobile as the metals can be released to the dissolved phase easily with $\mathrm{pH}$ variation, thus making the metal more bio-available. Temporal variation in the speciation is found to be related with discharge variations. No impact from the waste water treatment plant was observed, neither on the trace metal concentration, enrichment factors nor speciation.

This study suggests that a considerable amount of the metal studied could be associated with sulfidic phases which will be investigated in further studies. Nevertheless, the possible formation of sulfidic phases in the SPM accumulating during one month in the trap must be considered.

\section{ACKNOWLEDGEMENTS}

The authors would like to thank A. Bourgeault and the HBAN team in CemagrefAntony for sampling assistance, E. Robin for XRF analysis, N. Tisnerat-Laborde for decarbonatation discussion, C. Gautier and C. Hatté for POC and PON measurements, E. Douville for ICP-MS assistance, D. Thévenot for advice and corrections and J.-M. Mouchel, G. Morin and C. Quantin for helpful discussions. The Marnay-sur-Seine botanical garden and the SIAAP are thanked for giving access to the sampling sites located on their ground. For the acquisition of SEM data, we would like to thank A. Elmaleh and I. Estève at IMPMC and E. Robin at LSCE. We are also grateful to R. Hochreutener (MSc student) and to her research advisor G. Morin (IMPMC) as for organizing and preparing SEM analysis. The study is a contribution of the interdisciplinary research program on the environment PIREN-Seine and was also funded by the the Continental and Coastal Ecosphere French research program (EC2CO - INSU). Cindy Priadi acknowledges the French Foreign Affairs Ministry and PIREN Seine for her PhD scholarship. This is LSCE contribution number 4055.

\section{REFERENCES}

Afa, A. F. D. L. A., Les utilisations: Les marchés; http:// www.Aluminium-info.Com/fr/utilisations/marches. [Accessed 27-Apr 2010].

Audry, S.; Blanc, G.; Schäfer, J., (2006). Solid state partitioning of trace metals in suspended particulate matter from a river system affected by smelting-waste drainage Sci. Total. Environ., 363 (1-3), 216-236 (21 pages).

Azimi, S.; Rocher, V.; Garnaud, S.; Varrault, G.; Thevenot, D. R., (2005). Decrease of atmospheric deposition of heavy metals in an urban area from 1994 to 2002 (Paris, France). Chemosphere, 61 (5), 645-651 (7 pages).

Buzier, R.; Tusseau-Vuillemin, M. H.; Dit Meriadec, C. M.; Rousselot, O.; Mouchel, J. M., (2006). Trace metal speciation and fluxes within a major French wastewater treatment plant: Impact of the successive treatments stages Chemosphere, 65 (11), 2419-2426 (8 pages).

Carter, J.; Walling, D. E.; Owens, D. P. N.; Leeks, G. J. L., (2006). Spatial and temporal variability in the concentration and speciation of metals in suspended sediment transported by the River Aire, Yorkshire, UK. Hydrolog. Process., 20, 3007-3027 (21 pages).

Chen, J.; Gaillardet, J.; Louvat, P.; Huon, S., (2009). Zn isotopes in the suspended load of the Seine River, France: Isotopic variations and source determination. Geochimica et Cosmochimica Acta, 73 (14), 4060-4076 (18 pages).

Da Silva, I. S.; Abate, G.; Lichtig, J.; Masini, J. C., (2002). Heavy metal distribution in recent sediments of the TietêPinheiros river system in São Paulo state, Brazil. Appl. Geochem., 17 (2), 105-116 (12 pages).

Dali-Youcef, N.; Ouddane, B.; Derriche, Z., (2004). Metal partitioning in calcareous sediment of the Tafna river and its estuary (Algeria). Fresen. Environ. Bull., 13 (12B), 1500-1508 (9 pages).

Davis, A. P.; Shokouhian, M.; Ni, S., (2001). Loading estimates of lead, copper, cadmium, and zinc in urban runoff from specific sources. Chemosphere, 44 (5), 997-1009 (13 pages).

Du Laing, G.; Van de Moortel, A.; Moors, W.; De Grauwe, P.; Meers, E.; Tack, F.; Verloo, M., (2009). Factors affecting metal concentrations in reed plants (Phragmites australis) of intertidal marshes in the Scheldt estuary, Ecol. Eng. 35, 310-318 (9 pages).

Elbaz-Poulichet, F.; Seidel, J. L.; Casiot, C.; Tusseau-Vuillemin, M. H., (2006). Short-term variability of dissolved trace element concentrations in the Marne and Seine rivers near Paris. Sci. Total. Environ., 367 (1), 278-287 (10 pages).

Estebe, A.; Mouchel, J. M.; Thevenot, D. R., (1998). Urban runoff impacts on particulate metal concentrations in river Seine. Water Air Soil Pollut., 108 (1-2), 83-105 (23 pages).

Filgueiras, A. V.; Lavilla, I.; Bendicho, C., (2004). Evaluation of distribution, mobility and binding behaviour of heavy metals in surficial sediments of Louro river (Galicia, Spain) usingchemometric analysis: A case study. Sci. Total. Environ., 330 (1-3), 115-129 (15 pages).

Fujiyoshi, R.; Okamoto, T.; Katayama, M., (1994). Behavior of radionuclides in the environment . 2. Application of sequential extraction to $\mathrm{Zn}$ (II) sorption studies. Appl. Radiat. Isotopes, 45 (2), 165-170 (6 pages).

Gagnon, C.; Turcotte, P.; Vigneault, B., (2009). Comparative study of the fate and mobility of metals discharged in mining and urban effluents using sequential extractions on suspended solids. Environ. Geochem. Health, 31 (6), 657-671 (15 pages).

Galan, E.; Gomez-Ariza, J. L.; Gonzalez, I.; Fernandez-Caliani, J. C.; Morales, E.; Giraldez, I., (2003). Heavy metal partitioning in river sediments severely polluted by acid mine drainage in the Iberian Pyrite Belt. Appl. Geochem., 18 (3), 409-421 (13 pages).

Garnaud, S., (1999). Transfert et évolution géochimique de la pollution métallique en bassin versant urbain. Université Paris XII-Val de Marne, Créteil.

Gromaire-Mertz, M. C.; Garnaud, S.; Gonzalez, A.; Chebbo, G., (1999). Characterisation of urban runoff pollution in Paris. Water Sci. Tech. 39, 1-8 (8 pages).

Hassellov, M.; Von Der Kammer, F., (2008). Iron oxides as geochemical nanovectors for metal transport in soil-river systems. Elements, 4 (6), 401-406 (6 pages). 
Heijerick, D. G.; Janssen, C. R.; Karlen, C.; Wallinder, I. O.; Leygraf, C., (2002). Bioavailability of zinc in runoff water from roofing materials. Chemosphere, 47 (10), 1073-1080 (8 pages)

Hnatukova, P.; Benesova, L.; Kominkova, D., (2009). Impact of urban drainage on metal distribution in sediments of urban streams. Water Sci. Tech, 59 (6), 1237-1246 (10 pages).

Hochella, M. F.; White, A. F., (1990). Mineral-water interface geochemistry - an overview. Rev. Mineral. Geochem., 23 (1), 1-16 (16 pages).

Horowitz, A. J.; Meybeck, M.; Idlafkih, Z.; Biger, E., (1999). Variations in trace element geochemistry in the Seine River basin based on floodplain deposits and bed sediments. Hydrol. Process., 13 (9), 1329-1340 (12 pages).

Houhou, J.; Lartiges, B. S.; Hofmann, A.; Frappier, G.; Ghanbaja, J.; Temgoua, A., (2009). Phosphate dynamics in an urban sewer: A case study of Nancy, France. Water Res., 43 (4), 1088-1100 (13 pages).

Igbinosa, E. O.; Okoh, A. I., (2009). Impact of discharge wastewater effluents on the physico-chemical qualities of a receiving watershed in a typical rural community. Int. J. Environ. Sci. Tech., 6 (2), 175-182 (8 pages)

Igwe, J. C.; Abia, A. A.; Ibeh, C. A., (2008). Adsorption kinetics and intraparticulate diffusivities of $\mathrm{Hg}$, $\mathrm{As}$ and $\mathrm{Pb}$ ions on unmodified and thiolated coconut fiber. Int. J. Environ. Sci. Tech, 5 (1), 83-92 (10 pages)

Jain, C. K.; Gupta, H.; Chakrapani, G. J., (2008). Enrichment and fractionation of heavy metals in bed sediments of River Narmada, India. Environ. Monit. Assess., 141 (1-3), 35-47 (13 pages).

Jouvin, D.; Louvat, P.; Juillot, F.; Marechal, C. N.; Benedetti, M. F., (2009). Zinc isotopic fractionation: Why organic matters. Environ. Sci. Tech., 43 (15), 5747-5754 (8 pages).

Karbassi, A. R.; Monavari, S. M.; Bidhendi, G. R. N.; Nouri, J.; Nematpour, K., (2008). Metal pollution assessment of sediment and water in the Shur River. Environ. Monit. Assess., 147 (1-3), 107-116 (10 pages).

Larner, B. L.; Palmer, A. S.; Seen, A. J.; Townsend, A. T., (2008). A comparison of an optimised sequential extraction procedure and dilute acid leaching of elements in anoxic sediments, including the effects of oxidation on sediment metal partitioning. Anal. Chem. Acta., 608 (2), 147-157 (11 pages).

Le Cloarec, M. F.; Bonte, P. H.; Lestel, L.; Lefèvre, I.; Ayrault, S., (2009). Sedimentary record of metal contamination in the Seine River during the last century. Phys. Chem. Earth.parts A/B/C.

Lebreton, L.; Thevenot, D. R., (1992). Metal pollution release by road aerosols. Environ. Tech., 13 (1), 35-44 (10 pages).

Lesven, L.; Lourino-Cabana, B.; Billon, G.; Proix, N.; Recourt, P.; Ouddane, B.; Fischer, J.; Boughriet, A., (2009). Waterquality diagnosis and metal distribution in a strongly polluted zone of Deûle River (Northern France). Water. Air. Soil. Pollut., 198 (1), 31-44 (14 pages).

Li, Y.; Wang, X. L.; Huang, G. H.; Zhang, B. Y.;Guo, S. H., (2009). Adsorption of $\mathrm{Cu}$ and $\mathrm{Zn}$ onto Mn/Fe oxides and organic materials in the extractable fractions of river surficial sediments. Soil Sed. Contam.: Int. J., 18 (1), 87 - 101 (15 pages).

Lin, J. G.; Chen, S. Y., (1998). The relationship between adsorption of heavy metal and organic matter in river sediments. Environ. Int., 24 (3), 345-352 (8 pages).
Luoma, S. N.; Bryan, G. W., (1981). A statistical assessment of the form of trace-metals in oxidized estuarine sediments employing chemical extractants. Sci. Total. Environ., 17 (2), 165-196 (30 pages).

Luoma, S. N.; Rainbow, P. S., (2008). Metal Contamination in Aquatic Environments. Cambridge: Cambridge University Press. 573

Meybeck, A., (2003). Global analysis of river systems: From earth system controls to anthropocene syndromes. Philos Trans R. Soc. Lond. B. Biol. Sci., 358 (1440), 1935-1955 (21 pages).

Meybeck, M.; De Marsily, G.; Fustec, E., (1998). La Seine en Son Bassin: Fonctionnement Ecologique d'un Système Fluvial Anthropisé. Elsevier. 752

Meybeck, M.; Idlafkih, Z.; Fauchon, N.; Andreassian, V., (1999). Spatial and temporal variability of total suspended solids in the Seine basin. Hydrobiologia, 410, 295-306 (12 pages).

Meybeck, M.; Lestel, L.; Bonte, P.; Moilleron, R.; Colin, J. L.; Rousselot, O.; Herve, D.; De Ponteves, C.; Grosbois, C.; Thevenot, D. R., (2007). Historical perspective of heavy metals contamination $(\mathrm{Cd}, \mathrm{Cr}, \mathrm{Cu}, \mathrm{Hg}, \mathrm{Pb}, \mathrm{Zn}$ ) in the Seine River basin (France) following a DPSIR approach (1950-2005). Sci. Total. Environ., 375 (1-3), 204-231 (28 pages).

Mohiuddin, K. M.; Zakir, H. M.; Otomo, K.; Sharmin, S.; Shikazono, N., (2010) Geochemical distribution of trace metal pollutants in water and sediments of downstream of an urban river. Int. J. Environ. Sci. Tech , 7 (1), 17-28 (12 pages).

Morin, G.; Wang, Y. H.; Ona-Nguema, G.; Juillot, F.; Calas, G.; Menguy, N.; Aubry, E.; Bargar, J. R.; Brown, G. E., (2009). EXAFS and HRTEM evidence for As (III)-containing surface precipitates on nanocrystalline magnetite: Implications for as sequestration. Langmuir, 25 (16), 9119-9128 (10 pages).

Nwuche, C. O.; Ugoji, E. O., (2008). Effects of heavy metal pollution on the soil microbial activity. Int. J. Environ. Sci. Tech , 5 (3), 409-414 (6 pages).

Pepe, M.; Gaillard, A.; Harrault, L.; Groleau, A.; Benedetti, M. F., (2008). Les métaux dissous en Seine à paris. Paris.

Pernet-Coudrier, B.; Clouzot, L.; Varrault, G.; Tusseau-Vuillemin, M. H.; Verger, A.; Mouchel, J. M., (2008). Dissolved organic matter from treated effluent of a major wastewater treatment plant: Characterization and influence on copper toxicity. Chemosphere, 73 (4), 593-599 (8 pages).

Reimann, C.; De Caritat, P., (2005). Distinguishing between natural and anthropogenic sources for elements in the environment: Regional geochemical surveys versus enrichment factors. Sci. Total. Environ., 337 (1-3), 91-107 (17 pages).

Robert-Sainte, P.; Gromaire, M. C.; De Gouvello, B.; Saad, M.; Chebbo, G., (2009). Annual metallic flows in roof runoff from different materials: Test-bed scale in Paris conurbation. Environ. Sci. Tech., 43 (15), 5612-5618 (7 pages).

Rocher, V.; Azimi, S.; Moilleron, R.; Chebbo, G., (2004). Hydrocarbons and heavy metals in the different sewer deposits in the 'Le Marais' catchment (Paris, France): Stocks, distributions and origins. Sci. Total Environ., 323 (1-3), 107122 (16 pages).

Sekabira, K.; Oryem Origa, H.; Basamba, T. A.; Mutumba, G.; E. K., (2010). Assessment of heavy metal pollution in the urban stream sediments and its tributaries. Int. J. Environ. Sci. Tech., 7 (3), 435-446 (12 pages).

Sekabira, K.; Oryem Origa, H.; Basamba, T. A.; Mutumba, G.; E., K., (2010). Heavy metal assessment and water quality values in urban stream and rain water. Int. J. Environ. Sci. Tech., 7 (4), 759-770 (12 pages). 
Shah, B. A.; Shah, A. V.; Sigh, R. R., (2009). Sorption isotherms and kinetics of chromium uptake from wastewater using natural sorbent material, Int. J. Environ. Sci. Tech., 6 (1) , 77-90 (14 pages)

Siaap, (2007). Dossier du maitre d'ouvrage [online]. http:// www.debatpublic-station-epuration-seineaval.org/docs/pdf/ dossier-mo/doc-synthese-2.pdf.

Stumm, W.; Morgan, J. J., (1981). Aquatic Chemistry, 2 $2^{\text {ed. }}$ Toronto: Wiley-Interscience.780

Sutherland, R.; Tack, F., (2007). Sequential extraction of lead from grain size fractionated river sediments using the optimized BCR procedure. Water Air Soil Pollut., 184 (1), 269-284 (16 pages).

Taconet, J., (1996). Métaux fixés sur les matières en suspension dans le bassin de la Seine : Évolution des teneurs et des mobilités. DEA Sciences et Techniques de l'Environnement. MSc. Thesis Université Paris XII: Val de Marne Créteil.

Taylor, K. G.; Owens, P. N., (2009). Sediments in urban river basins: A review of sediment-contaminant dynamics in an environmental system conditioned by human activities. J. Soils. Sediments, 9 (4), 281-303 (23 pages).

Tessier, L.; Bonté, P., (2002). Suspended sediment transfer in Seine River watershed, France: A strategy using fingerprinting from trace elements. Science for Water Policy: The implications of the Water Framework Directive, Norwich, 79-99 (21 pages).

Thévenot, D.; Meybeck, M.; Lestel, L., (2002). Métaux lords: Des bilans en mutation. Paris.
Thévenot, D. R.; Moilleron, R.; Lestel, L.; Gromaire, M. C.; Rocher, V.; Cambier, P.; Bonté, P.; Colin, J. L.; De Pontevès, C.; Meybeck, M., (2007). Critical budget of metal sources and pathways in the Seine River basin (1994-2003) for Cd, $\mathrm{Cr}, \mathrm{Cu}, \mathrm{Hg}, \mathrm{Ni}, \mathrm{Pb}$ and Zn. Sci. Total Environ., 375 (1-3), 180-203 (24 pages).

Tongtavee, N.; Shiowatana, J.; Mclaren, R. G., (2005). Fractionation of lead in soils affected by smelter activities using a continuous-flow sequential extraction system. Int. J. Environ. Anal. Chem., 85 (8), 567-583 (17 pages).

Tusseau-Vuillemin, M. H.; Buzier, R.; Meriadec, C. D.; Chardon, I.; Elbaz-Poulichet, F.; Seidel, J. L.; Mouchel, J. M.; Varrault, G., 2005. Du réseau à la rivière et de la Marne à Andrésy : Métaux labiles, dissous et particulaires. Paris.

Tusseau-Vuillemin, M. H.; Gourlay, C.; Lorgeoux, C.; Mouchel, J. M.; Buzier, R.; Gilbin, R.; Seidel, J. L.; Elbaz-Poulichet, F., (2007). Dissolved and bioavailable contaminants in the Seine River basin. Sci. Total Environ., 375 (1-3), 244-256 (13 pages). USGS, (2010). Aluminum: Statistics and information.

Vieira, J. S.; Botelho, C. L. M. S.;Boaventura, R. A. R., (2009). Trace metal fractionation by the sequential extraction method in sediments from the Lis river (Portugal). Soil Sed. Contam.: Int. J., 18 (1), 102 - 119 (18 page).

Zhu, T.; Li, J.; Jin, Y. Q.; Liang, Y. H.; Ma, G. D., (2009) Gaseous phase benzene decomposition by non-thermal plasma coupled with nano titania catalyst. Int. J. Environ. Sci. Tech, 6 (1),141-148 (8 pages)

\section{AUTHOR (S) BIOSKETCHES}

Priadi, C., is a PhD scholar in Environmental geosciences at the Laboratoire des Sciences du Climat et de l'Environnement (LSCE/IPSL, CEA-CNRS-UVSQ). Email : cindy.priadi@lsce.ipsl.fr

Ayrault, S., is a researcher in trace element environmental cycles at the Laboratoire des Sciences du Climat et de l'Environnement (LSCE IPSL, CEA-CNRS-UVSQ). Email : sophie.ayrault@Isce.ipsl.fr

Pacini, S., (MSc) performed her $3^{\text {rd }}$ year engineering internship at the Laboratoire des Sciences du Climat et de l'Environnement (LSCE/ IPSL, CEA-CNRS-UVSQ). Email: stephanie.pacini@gmail.com

Bonté, P., is a retired senior scientist in soil erosion and particles transfer in river at the Laboratoire des Sciences du Climat et de l’Environnement (LSCE/IPSL, CEA-CNRS-UVSQ). Email : bonté@lsce.ipsl.fr

How to cite this article: (Harvard style)

Priadi, C.; Ayrault, S. ; Pacini, S. ; Bonte, P. (2011). Urbanization impact on metals mobility in riverine suspended sediment: Role of metal oxides. Int. J. Environ. Sci. Tech., 8 (1), 1-18. 